\title{
Dermacentor reticulatus: a vector on the rise
}

\author{
Gábor Földvári ${ }^{*}$, Pavel Široký²,3, Sándor Szekeres', Gábor Majoros ${ }^{1}$ and Hein Sprong ${ }^{4}$
}

\begin{abstract}
Dermacentor reticulatus is a hard tick species with extraordinary biological features. It has a high reproduction rate, a rapid developmental cycle, and is also able to overcome years of unfavourable conditions. Dermacentor reticulatus can survive under water for several months and is cold-hardy even compared to other tick species. It has a wide host range: over 60 different wild and domesticated hosts are known for the three active developmental stages. Its high adaptiveness gives an edge to this tick species as shown by new data on the emergence and establishment of $D$. reticulatus populations throughout Europe. The tick has been the research focus of a growing number of scientists, physicians and veterinarians. Within the Web of Science database, more than a fifth of the over 700 items published on this species between 1897 and 2015 appeared in the last three years (2013-2015). Here we attempt to synthesize current knowledge on the systematics, ecology, geographical distribution and recent spread of the species and to highlight the great spectrum of possible veterinary and public health threats it poses. Canine babesiosis caused by Babesia canis is a severe leading canine vector-borne disease in many endemic areas. Although less frequently than /xodes ricinus, D. reticulatus adults bite humans and transmit several Rickettsia spp., Omsk haemorrhagic fever virus or Tick-borne encephalitis virus. We have not solely collected and reviewed the latest and fundamental scientific papers available in primary databases but also widened our scope to books, theses, conference papers and specialists colleagues' experience where needed. Besides the dominant literature available in English, we also tried to access scientific literature in German, Russian and eastern European languages as well. We hope to inspire future research projects that are necessary to understand the basic life-cycle and ecology of this vector in order to understand and prevent disease threats. We conclude that although great strides have been made in our knowledge of the eco-epidemiology of this species, several gaps still need to be filled with basic research, targeting possible reservoir and vector roles and the key factors resulting in the observed geographical spread of D. reticulatus.
\end{abstract}

Keywords: Dermacentor reticulatus, Ecology, Geographical distribution, Spread, Epidemiology, Host associations, Europe, Asia, Babesia canis, Omsk haemorrhagic fever virus

\section{Background}

An ideal arthropod vector has a high reproduction rate, an ability to survive and even spread within variable habitats and an opportunity to host and transmit a great variety of pathogens. All these conditions are perfectly met by the hard tick species Dermacentor reticulatus. Fertilised females lay up to 7,200 eggs [1] and adults possess an extreme tolerance to the changing environment. Adapted to river basins among other habitats, they survive under water containing organic residues for up to one month and in cool and clean water for more than 100 days [2]. In contrast

\footnotetext{
*Correspondence: FoldvariGabor@gmx.de

'Department of Parasitology and Zoology, Faculty of Veterinary Science,

Szent István University, Budapest, Hungary

Full list of author information is available at the end of the article
}

to dipteran vectors, adult $D$. reticulatus specimens have a long lifespan; they have been shown to survive for up to four years without taking a blood meal [3]. They are even able to tolerate $-10{ }^{\circ} \mathrm{C}$ for 150 days under laboratory conditions [4] and are shown to be active during the winter in many climatic zones at temperatures at which Ixodes ricinus is not active [5]. Furthermore, the speed of its developmental rate from larvae to nymphs and again to adults surpasses I. ricinus [6]. Dermacentor reticulatus attaches and feeds on a wide range of hosts, including wild and domesticated mammals, for days at a time enabling the tick to spread over large distances. The high adaptiveness of this species is exemplified by the recent new establishments of $D$. reticulatus populations in many countries and regions of Europe. The multitude of pathogens that can (potentially) be transmitted by this vector highlights the 
long-shared evolutionary history of several viruses, bacteria and protists with $D$. reticulatus and its hosts. First of all, it is a vector of pathogens causing animal health problems. Canine babesiosis caused by Babesia canis is a severe leading canine vector-borne disease in many endemic areas. Although less frequently than I. ricinus, $D$. reticulatus adults bite humans and can transmit several Rickettsia spp., Omsk haemorrhagic fever virus and tick-borne encephalitis virus. Here we attempt to summarize current knowledge on the systematics, ecology, geographical distribution and recent expansion of $D$. reticulatus, and highlight the great spectrum of possible veterinary and public health threats posed by this tick species, which is currently invading new areas.

\section{Systematics}

Dermacentor reticulatus (Fabricius, 1794) is a metastriate tick species belonging to the almost globally cosmopolitan genus Dermacentor (consisting of 35 currently recognised species), subfamily Rhipicephalinae, family Ixodidae, order Ixodida, subclass Acari, class Arachnida $[7,8]$. It has previously been known by several junior synonym names (see e.g. Guglielmone and Nava [9]), with Dermacentor pictus (Hermann, 1804) as one of the most widespread of these, especially in the former Soviet Union and eastern Europe [10]. It was originally named Acarus reticulatus Fabricius, 1794 and given its current status by Koch in 1844 [11]. English names of this species used in scientific publications are ornate cow tick [12], ornate dog tick [13], meadow tick [14] or marsh tick [15-17].

Dermacentor reticulatus can be unambiguously distinguished from D. marginatus, despite its morphological resemblance [18]. Although a bit smaller than $D$. marginatus, $D$. reticulatus is considerably larger than most Ixodes and Haemaphysalis ticks. Males (4.2$4.8 \mathrm{~mm})$ are larger than females $(3.8-4.2 \mathrm{~mm})$ when unfed, however a fully fed female reaches $1 \mathrm{~cm}$ [12]. Nymphs are 1.4-1.8 $\mathrm{mm}$ and larvae only $0.5 \mathrm{~mm}$ in size [4].

There are excellent keys $[12,13]$ available for the morphological identification of adults using some key features such as the palps and coxae, as shown on Figs. 1, 2, 3 and 4. Like all species of Dermacentor, D. reticulatus has relatively short mouthparts with a basis capitulum of straight lateral margins, both sexes have white enamel ornamentation and the males have very large fourth coxae $[10,12$, 13]. As D. reticulatus can sometimes be found on the same host with $D$. marginatus, differentiation of the two species is important. For both sexes, the most important feature is the presence of a palpal spur in $D$. reticulatus (vs absent in D. marginatus) (Figs. 1 and 2). For females, most prominent details are the shape of porose areas, the shape of the gap between internal and external spurs on coxa I and the size of the lips in the genital aperture (Fig. 1). For males, cornua are long in D. reticulatus (vs short in D. marginatus) and the lateral groove is in the form of punctations only in $D$. reticulatus (no groove visible, see Fig. 2) [13]. Compared to adults, larvae (Fig. 5a) and nymphs (Fig. 5b), are difficult to identify. They resemble Rhipicephalus spp. immatures, especially when engorged. Usually, D. reticulatus immatures are only accessible as engorged specimens because they cannot be collected from the vegetation (see also section "Life-cycle and ecology" below). Engorgement modifies their morphological characters and identification requires mounting and careful examination of the specimen under light microscopy by an experienced entomologist (Fig. 5).

\section{Life-cycle and ecology}

Our current understanding of life-cycle traits and ecological aspects of $D$. reticulatus is rather limited compared to the well-studied Ixodes ricinus or Ixodes scapularis. This may be partly due to the hidden nature of the larvae and nymphs of this species. Although it is a three-host tick, as is I. ricinus, in contrast to the latter species the larvae and nymphs of $D$. reticulatus are reportedly nidicolous, while adults show an exophilic (non-nidicolous) behaviour [10, 19, 20]. For this reason, immatures, in contrast to adults, are rarely collected by flagging, with some exceptions [5]. Adults, in contrast, are easy to collect by flagging where they are abundant, and thus it is easier to gain phenology data for them. To assess seasonality or population dynamics of immatures, their preferred hosts have to be investigated.

Larvae usually appear on small mammal hosts in MayJune, with their highest abundance in June-July in temperate Europe $[6,10,19,20]$. Dermacentor reticulatus was shown to have a higher developmental rate compared to I. ricinus but a relatively low mortality rate [10]. Engorged larvae moult and give rise to feeding nymphs within a month and the whole generation is completed within a few months in nature [6]. The relatively rapid development is also obvious from a table that lists 37 hard tick species maintained in the laboratory, among which $D$. reticulatus was shown to have one of the shortest life-cycles [7]. The fact that nymphs are usually active only for one month (July-August) $[6,19,20]$ results in a very small window of opportunity for cofeeding larvae and nymphs. Whereas only $3 \%$ of $I$. ricinus nymphs were recorded on hosts without conspecific larvae, $28 \%$ of $D$. reticulatus nymphs occurred in the absence of larvae [6]. Another difference from the ecology of $I$. ricinus is that while $I$. ricinus nymphs and larvae feeding on the same host probably represent two different generations, separated in age by a year, $D$. reticulatus nymphs and larvae are part of the same generation, maturing within the same summer [21]. 


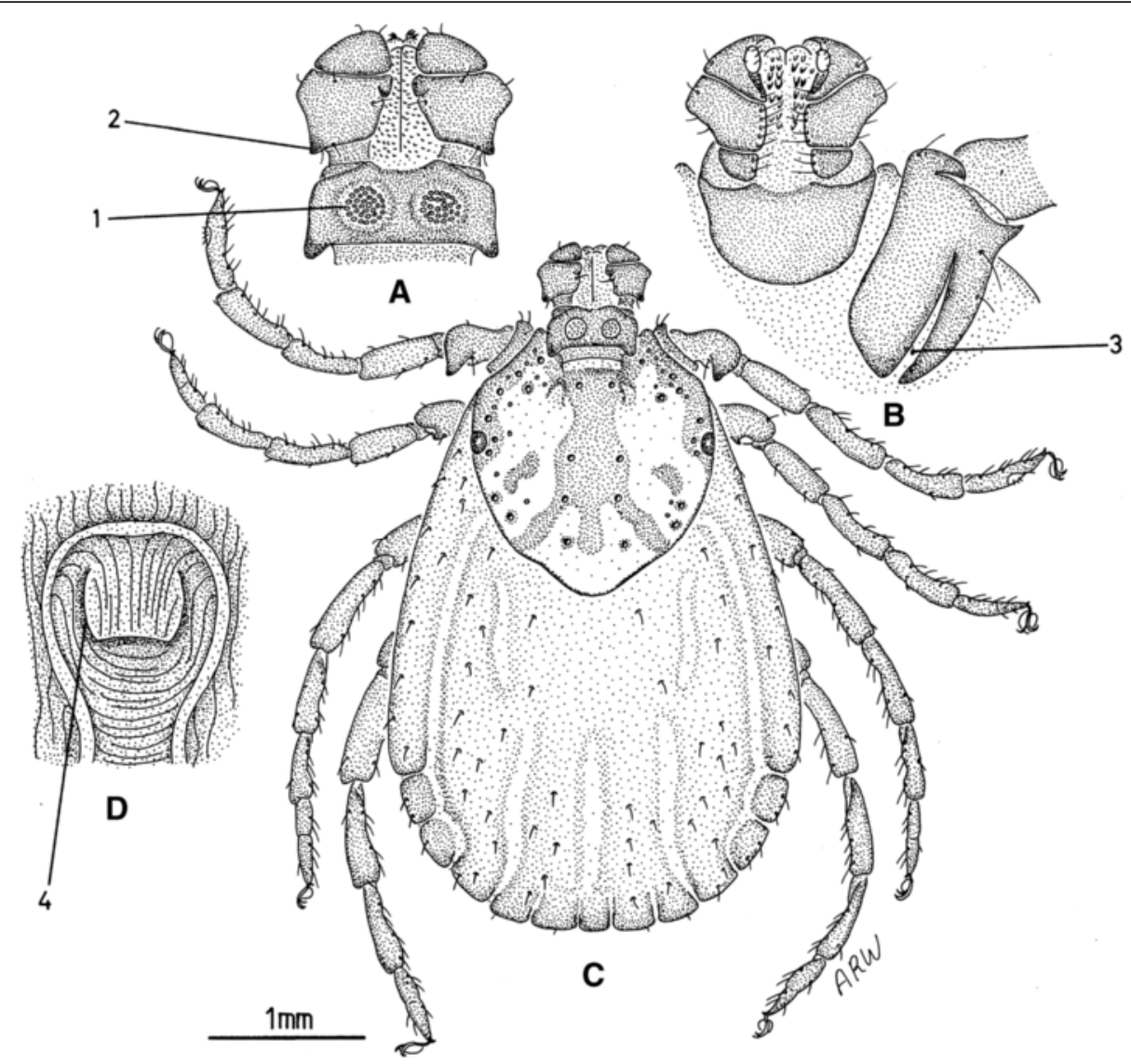

Fig. 1 Most important morphological characters of female Dermacentor reticulatus. a Dorsal capitulum. b Ventral coxa. c Dorsal body. d Genital aperture. 1, Porose areas shape is a broad oval (nearly circular). 2, Palp articles 2 posterior spur is present on the dorsal surface. 3, Coxae 1 gap between external and internal spurs is narrow (also the external spur is as long as the internal spur). 4, Genital aperture posterior lips have a broad $U$ shape (this shape is truncated posteriorly). Original drawings by Alan R. Walker [13]

Laboratory data show that larvae feed for 2.5-6 days and nymphs for 4-12 days [22-24]. The large accumulation of endosomes (or inclusion bodies in the gut epithelium) [7] during immature feeding and rapid digestion is associated with their short premoulting period [23]. In the more slowly moulting I. ricinus, food inclusions are only formed after detachment [23].

Adults are mainly active from March with a peak in April; they are less abundant during the summer (they completely disappear from vegetation in continental climates) and have a second activity peak in SeptemberOctober [25-27]. During the winter they undergo diapause which is different from quiescence and is defined as a neurohormonally-mediated dynamic state of low metabolic activity [28]. The relatively early activation of $D$. reticulatus adults after winter diapause is associated with their ability to withstand low temperatures [29] which results in an evolutionary advantage compared to other ticks. Adult $D$. reticulatus follow an ambush strategy to find their hosts [30]. They climb onto weeds, grasses, bushes, or other leafy vegetation (as shown in
Additional file 1: Video 1, Additional file 2: Video 2) to wait for passing hosts. The average height for this questing behaviour is $55 \mathrm{~cm}$ [19]. Since adult female and male specimens of $D$. reticulatus are three and five times larger respectively than I. ricinus [5], they are often visible at the tips of the vegetation (Fig. 6) and can be easily collected by hand during their activity period. Because of their highly sensitive chemical receptors [30] they are attracted by host odours, and are therefore often associated with tracks used by wildlife, dogs and humans [5, 31]. At preferred sites the number of adults collected per hour per flag can reach 222 [32]. Many authors observed female predominance in questing tick populations [5, 33-35] possibly resulting from their metastriate mating strategy, i.e. males need to find a host and tend to spend more time on the host while fertilising several females [7, 36]. Furthermore, females of $D$. reticulatus may have a higher survival rate as they were shown to be more resistant to desiccation than males, as proven in laboratory experiments [37]. In addition, females were shown to predominate also in 

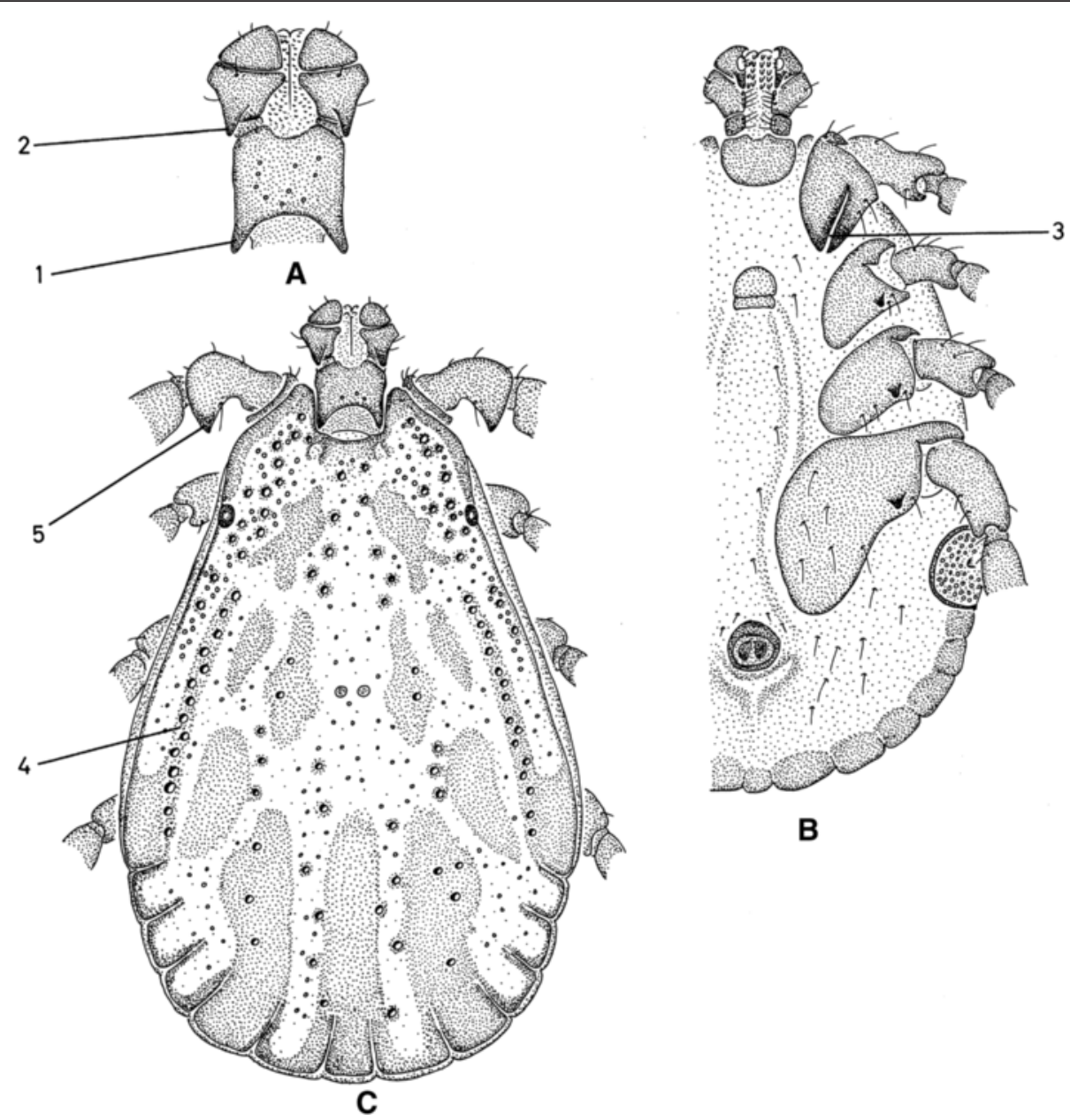

B

Fig. 2 Most important morphological characters of male Dermacentor reticulatus. a Dorsal capitulum. b Ventral body. c Dorsal body. 1, Cornua length is long. 2, Palp articles 2 posterior spur is long on the dorsal surface. 3, Coxae 1 gap between external and internal spurs is narrow (also the external spur is as long as the internal spur). 4, Lateral groove type is in the form of punctations only (there is no groove visible). 5, Trochanter 1 posterior spur is long on the dorsal surface. Original drawings by Alan R. Walker [13]
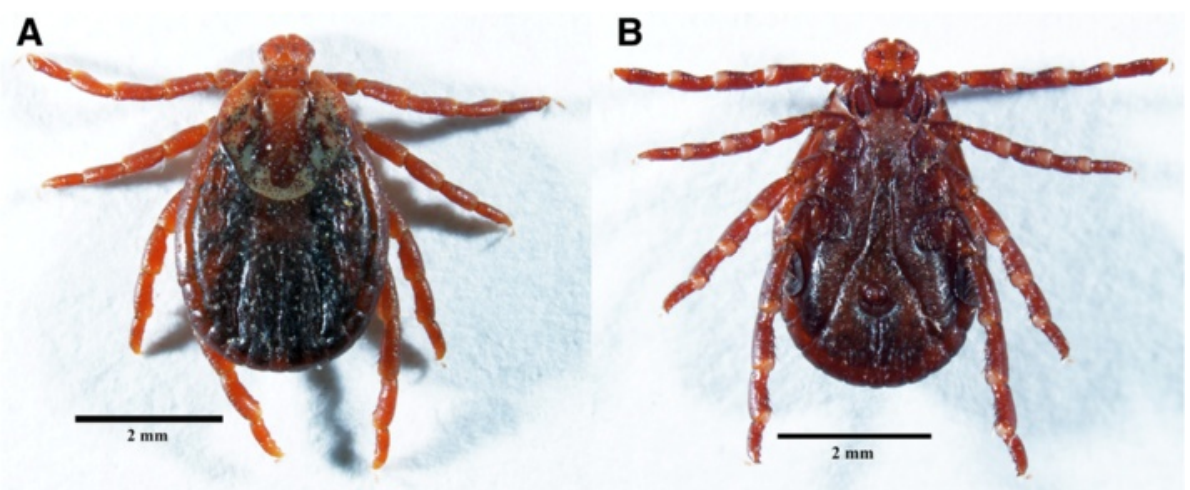

Fig. 3 Photomicrograph of female Dermacentor reticulatus. a Dorsal view. b Ventral view 

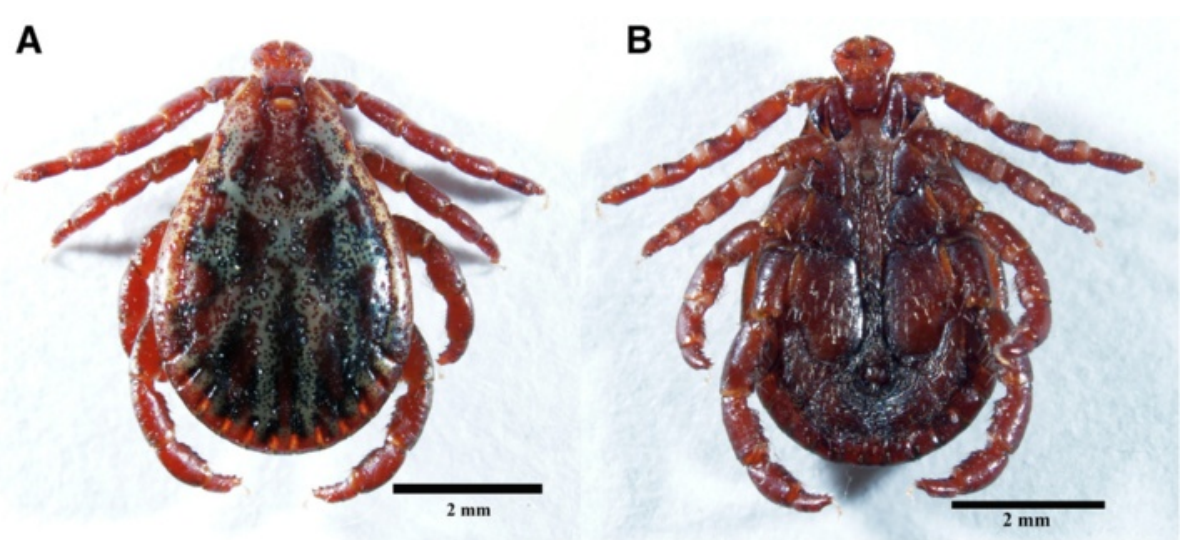

Fig. 4 Photomicrograph of male Dermacentor reticulatus. a Dorsal view. b Ventral view

artificially bred groups of $D$. reticulatus [19] even in lines derived from single, fertilised females suggesting the existence of a genetic mechanism.

Adults prefer medium-sized and large mammals and tend to feed in clusters, resulting in macroscopically visible lesions with local inflammation [38]. The aggregated feeding is probably a consequence of aggregationattachment pheromones as shown in other metastriate ticks [7] but not studied in D. reticulatus. Females feed for $7-15$ days under laboratory conditions $[1,22-24,38$, 39]. Balashov [23] noted that $D$. reticulatus females usually attach on the first day but 2-3 days are needed in autumn and winter leading to 1-2 days longer feeding in autumn and 3-4 days longer feeding in winter compared to spring. Overwintering on the host, an unusual trait among three-host ticks, has also been reported for this species [40]. Ticks were observed to remain attached on domestic animals from autumn until the onset of warm spring weather, during which period they do not feed [23]. Another impressive trait is the amount of blood ingested. Although larger species (e.g.
D. marginatus or Hyalomma spp.) are able to take larger blood meals, D. reticulatus is the only one for which it has been observed that its faecal weight during feeding may exceed that of the engorged tick [23].

Male individuals also attach and are able to feed for 3-5 days [23] (Hans Dautel, personal communication) and fertilise females exclusively on the host. Dermacentor reticulatus males remain on the host for 2-3 months [23] and are considered important vectors of several pathogenic agents due to their intermittent feeding behaviour which is a relevant epidemiological difference compared with Ixodes spp. males. Fully-fed fertilised females drop to the ground and lay 3,000-7,200 eggs while covering them with the secretion of the Genés organ, protecting the eggs from drying out [1, 41]. Oviposition lasts for 6-25 days and the new generation of larvae will hatch from the egg batch after 12-19 days [22]. The whole life-cycle (Fig. 7) can be completed within the same year or, if the unfed adults overwinter (behavioural diapause), within two years [22]. Nosek [42] observed that usually unfed adults overwinter,

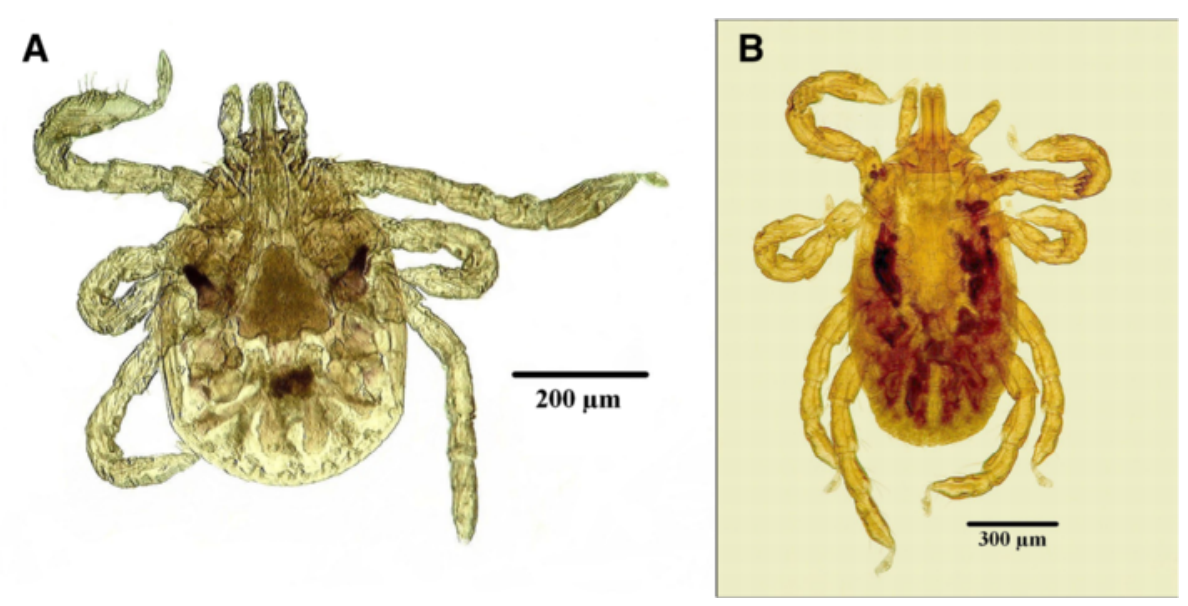

Fig. 5 Photomicrograph of Dermacentor reticulatus. a Larva. b Nymph 


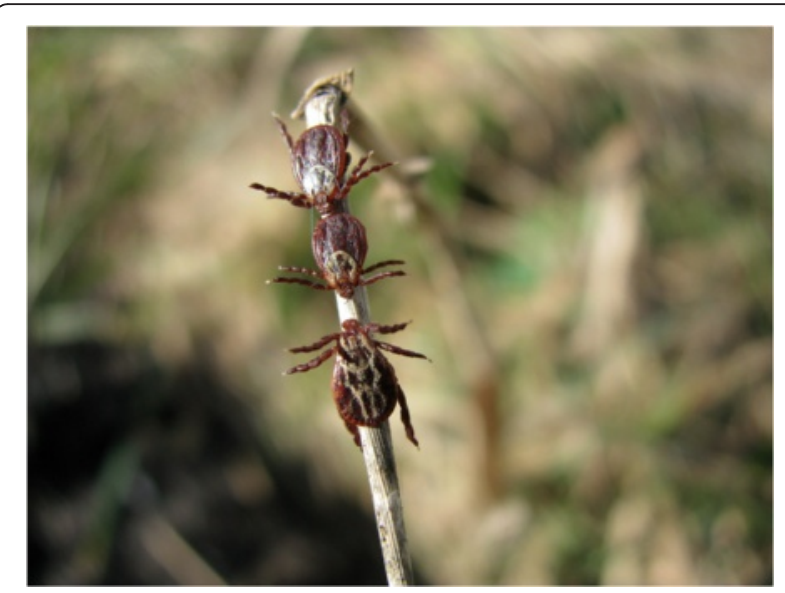

Fig. 6 Two female and a male host seeking Dermacentor reticulatus

however, overwintering of engorged females, engorged nymphs and engorged larvae also occurred during the sixyear study [42]. If engorged nymphs overwinter and moult during next spring, the size of the resulting adult is considerably smaller compared to average [42]. Overwintered engorged females are also smaller in size and weight. [42] According to the six years of observation, overwintering unfed females represented the general life-cycle and the overwintering of engorged females, nymphs and larvae was observed less frequently, e.g. spring emergence of freshly moulted adults occurred in $5 \%$ of individuals [42]. Both behavioural and developmental diapause described in this species are obviously biological adaptations to increase chances for survival and consequently to prolong the tick lifespan [23].

All stages of $D$. reticulatus are more seasonal compared to I. ricinus. However, if the winter is relatively mild, adults of the former are active throughout the year $[5,25,43]$. During a 24-hour monitoring of questing at a marsh site in March in Wales the minimum temperature at which $D$. reticulatus adults were recorded active was $3.3{ }^{\circ} \mathrm{C}$ (at $9 \mathrm{am}$ ) and the minimum overnight temperature was $-5.4{ }^{\circ} \mathrm{C}$ with some adults being active even when the underlying sand surface was frozen. The questing-temperature limit also depends on the tick's physiological age (Olaf Kahl, personal communication). However, considerable variation can be observed in the seasonal activity of adults according to differences in climatic conditions. It has experimentally been observed that adults were still alive 2.5 years after moulting (third spring) indicating a great tolerance to starvation [44]. According to Olsuf'ev [3], adults can survive for as long as 3-4 years in the absence of hosts in nature [3]. At the eastern end of its range (western Siberia) adults were only active during the brief spring (April-June) with brief autumn activity occurring almost immediately afterwards (July-September) and no activity during the rest of the year. At the western end of the range (Wales, France), they were active for most of the year with a short summer diapause (two months, June-August) and a brief winter period of inactivity (one

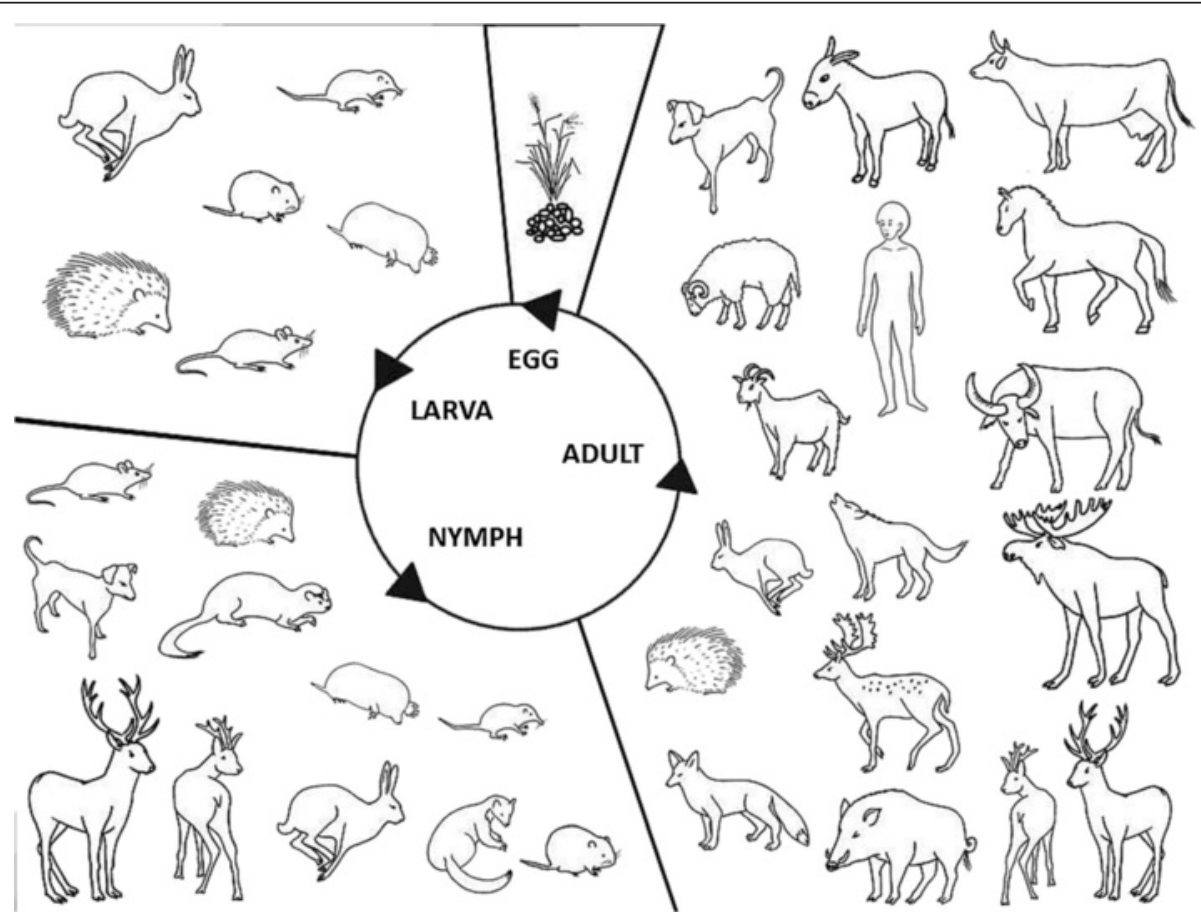

Fig. 7 Life-cycle of Dermacentor reticulatus 
month, December-January) [5, 45]. The latter does not qualify as a true diapause [46] since $D$. reticulatus adults can reappear relatively quickly during warmer winter days $[5,33]$. The winter diapause found in central Europe [22], eastern Europe and western Siberia [33] is likely to be a response to the harsh winter conditions, while such a diapause is not required on the western limit of the species range. In temperate Europe, adults are most active in April-May, activity declines during summer, and there is a second, usually smaller activity peak in SeptemberOctober $[4,19,22,25,26,33,45]$. Photoperiod is clearly of underlying importance in controlling behavioural diapause (i.e. suppression of host-seeking activity) $[47,48]$. It may be that there is an East-West cline in the inductive photoperiod. Alternatively, the diapause in Europe may result from a temperature-photoperiod interaction in which mild winter conditions are not sufficient to induce diapause [5]. Cessation of adult questing activity at the end of spring may be associated with temperatures but reactivation in the autumn occurs before temperatures fall indicating the importance of photoperiod (decreasing daylight) [5].

During a field study in Wales, UK [5] the observed $D$. reticulatus population exhibited a plastic behavioural response (variation in seasonal activity) within a local area. Macro-temperature appeared to have exerted the predominant influence on ticks at the dune sites, whereas photoperiod was the only macroclimate variable with a significant effect on activity at the marsh site. A microclimatic effect of vegetation temperature and humidity on tick activity was found at the dune site and only vegetation temperature had an effect at the marsh site. Such variation in behaviour within a population is likely to reflect individual responses to microenvironmental cues, i.e. phenotypic plasticity of the species.

Larvae and nymphs usually use the same, predominantly small, mammalian host (Table 1; Fig. 7) for their blood meal. In Europe, D. reticulatus immatures are found at higher mean intensity and prevalence on voles than on mice $[5,6,19-21]$. This host-association is the opposite to that in I. ricinus which occurs more frequently on mice compared to voles [20,49]. Hedgehogs, shrews, moles, hares and rabbits are typical hosts, and birds $[50,51]$ can be occasional hosts for $D$. reticulatus larvae, while nymphs, in addition to these hosts, might feed on weasels, polecats, cervids, goats, dogs $[10,12,22$, $52]$ and occasionally on birds $[22,50,51,53]$ and humans $[4,54-56]$. Szymanski [33] suggested that different species may act as the main host depending on geographical location and habitat type. In open areas in Siberia, the narrow-headed vole (Microtus gregalis) was the main host, whereas in forest areas, root voles (Microtus oeconomus), northern red-backed voles (Myodes rutilus) and common shrews (Sorex araneus) were the main hosts. Host species was of more importance than host abundance at study sites in Poland. Although the common shrew was the most abundant host, root voles and field voles (Microtus agrestis) fed most of the nymphs. Reports of larvae [57, 58] and even a female [57] from lizards and a nymph from a frog [57] are either mistakes, erroneous translations from Russian or accidental infestations [4, 8]. Neumann [59] listed two bat species and also rhinoceros and hippopotamus as hosts. Since these records have never been confirmed by others, they cannot be considered as bona fide host-associations.

Adults use an even wider range of host animals (Table 1; Fig. 7). Wild hosts include various cervids, wild boars, foxes, golden jackals, wolves, hedgehogs, hares and rabbits. Domesticated animals are equally important as hosts or even the dominant $[25,60]$ hosts (e.g. in cities or agricultural areas) for adults and are represented mostly by dogs, horses, donkeys, cattle, buffalo, sheep, goats and pigs [10, 12, 22, 61]. Like immatures, adults possess the adaptive trait to use different vertebrates as dominant (often domesticated) hosts depending on their local availability [60]. Humans can also be occasional hosts of adults [61-66] increasing the public health importance of pathogens harboured by these ticks. The role of immatures in their epidemiology is largely unknown.

Concerning ecological aspects, Nosek [22] has already emphasised that original ecosystems have been changed or greatly affected by human activity across the distribution range of $D$. reticulatus. Although some authors [19] referred to this tick as a species with restricted habitat use, on a geographical scale it in fact exists in a wide range of habitat types. These include meadows and open mixed or oak forests $[67,68]$, clearings $[19,22]$ river basins, swampy mixed woods, lakeshore vegetation $[15,22$, 69], pastured land, heath, scattered scrub, suburban wasteland [31, 70] and coastal dune systems. [5] Dermacentor reticulatus is rarely found in closed, dark forests [31] such as the taiga [22, 71] and coniferous forests [72]. It apparently prefers riparian forests (river basins), ecotones between fields and mixed deciduous forests, forest paths and lake shore vegetation [22, 32, 73]. The presence of eyes and the relatively bright and patchy colouration are obvious morphological adaptations to living in open habitats with a relatively high insolation. Its association with wet habitats is clearly shown by its resistance to water. Eggs survive in pools of rainwater [74] and adults remain alive during periodic floods that are often characteristic for their preferred habitats [67]. Accordingly, D. reticulatus can also be collected from the common reed (Phragmites australis) in wetland habitats [75].

A recent ecological approach [35] found empirical evidence that the niches of $D$. reticulatus and I. ricinus segregate along temperature and moisture axes. Based on 25 habitat variables derived from digital maps using 
Table 1 Reported hosts of Dermacentor reticulatus

\begin{tabular}{|c|c|c|c|}
\hline Host & Stage $^{a}$ & Area & References \\
\hline Yellow-necked mouse (Apodemus flavicollis) & $L, N$ & Europe & {$[22,33]$} \\
\hline Wood mouse (A. sylvaticus) & $L, N$ & Europe & {$[22,279,280]$} \\
\hline Striped field mouse (A. agrarius) & $L, N$ & Eurasia & {$[22,279-281]$} \\
\hline Northern birch mouse (Sicista betulina) & $L, N$ & Northern Europe, Western Russia & [281] \\
\hline European pine vole (Microtus subterraneus) & $L, N$ & Europe & [22] \\
\hline Common vole (Mi. arvalis) & $L, N$ & Europe, Western Russia & {$[22,280,281]$} \\
\hline Narrow-headed vole (Mi. gregalis) & $L, N$ & Asia & {$[279]$} \\
\hline Root vole (Mi. oeconomus) & $L, N$ & Eurasia & {$[279,281]$} \\
\hline Field vole (Mi. agrestis) & $L, N$ & Europe, Western Russia & [281] \\
\hline Major's pine vole (Mi. majori) & $L, N$ & Caucasus, North-western Iran & [282] \\
\hline Bank vole (Myodes glareolus) & $L, N$ & Europe, Western Russia & {$[22,280,281]$} \\
\hline Northern red-backed vole (My. rutilus) & $L, N$ & Eurasia & {$[279]$} \\
\hline European water vole (Arvicola amphibius) & $L, N$ & Eurasia & [72] \\
\hline Eurasian harvest mouse (Micromys minutus) & $L, N$ & Eurasia & [281] \\
\hline European hamster (Cricetus cricetus) & $L, N$ & Europe, South-western Russia & [279] \\
\hline Muskrat (Ondatra zibethicus) & L & Eurasia & {$[279]$} \\
\hline Red-cheeked ground squirrel (Spermophilus erythrogenys) & L & Asian steppes & {$[279]$} \\
\hline European rabbit (Oryctolagus cuniculus) & $L, N, A$ & Europe & [22] \\
\hline European hare (Lepus europeus) & $L, N, A$ & Eurasia & {$[22,283]$} \\
\hline Common shrew (Sorex araneus) & $L, N, A$ & Europe, Russia & {$[22,72,279-281,284]$} \\
\hline Eurasian pygmy shrew (So. minutus) & $L, N$ & Europe, Russia & {$[22,281]$} \\
\hline Eurasian water shrew (Neomys fodiens) & $L, N$ & Europe, Russia & {$[22,281]$} \\
\hline European mole (Talpa europea) & $L, N$ & Europe, Western Russia & [281] \\
\hline Northern white-breasted hedgehog (Erinaceus roumanicus) & $L, N, A$ & Eastern Europe, Western Russia & {$[22,283]$} \\
\hline European hedgehog (E. europeus) & $\mathrm{N}, \mathrm{A}$ & Western Europe & [283] \\
\hline Least weasel (Mustela nivalis) & $L, N, A$ & Eurasia & {$[22,279-281]$} \\
\hline Stoat (Mu. erminea) & $\mathrm{N}$ & Eurasia & {$[279]$} \\
\hline European polecat (Mu. putorius) & $\mathrm{N}, \mathrm{A}$ & Europe, Western Russia & {$[22,285]$} \\
\hline European badger (Meles meles) & A & Europe & {$[286]$} \\
\hline Racoon dog (Nyctereutes procyonoides) & A & Europe & {$[140]$} \\
\hline Roe deer (Capreolus capreolus) & $N^{b}, A$ & Europe, & {$[22,59,69,280,287,288]$} \\
\hline Fallow deer (Dama dama) & A & Europe & {$[62]$} \\
\hline Red deer (Cervus elaphus) & $N^{b}, A$ & Europe, Western Asia & {$[22,59,279-281,285,288,289]$} \\
\hline Moose (Alces alces) & A & Eurasia & {$[68,289]$} \\
\hline European bison or wisent (Bison bonasus) & A & Europe, Western Russia & {$[60,144,290-292]$} \\
\hline Wild boar (Sus scrofa) & A & Eurasia & {$[22,59,61,70,285,289,293]$} \\
\hline Red fox (Vulpes vulpes) & A & Eurasia & {$[22,31,61,286,294-296]$} \\
\hline Golden jackal (Canis aureus) & A & Eurasia & [52] \\
\hline Gray wolf (Canis lupus) & A & Eurasia & [42] \\
\hline Iberian wolf (Canis lupus signatus) & A & Iberian Peninsula & {$[286]$} \\
\hline Common starling (Sturnus vulgaris) & $N^{b}$ & Eurasia & [50] \\
\hline Blackbird (Turdus merula) & $N^{b}$ & Eurasia & [50] \\
\hline Mistle thrush (Turdus viscivorus) & $L^{b}$ & Eurasia & [50] \\
\hline Eurasian jay (Garrulus glandarius) & $N^{b}$ & Eurasia & [22] \\
\hline
\end{tabular}


Table 1 Reported hosts of Dermacentor reticulatus (Continued)

\begin{tabular}{llll}
\hline Medow pipit (Anthus pratensis) & $\mathrm{N}^{\mathrm{b}}$ & Eurasia & {$[53]$} \\
Tree pipit (Anthus trivialis) & $\mathrm{L}^{\mathrm{b}}, \mathrm{N}^{\mathrm{b}}$ & Eurasia & {$[51]$} \\
Song thrush (Turdus philomelos) & $\mathrm{N}^{\mathrm{b}}$ & Eurasia & {$[51]$} \\
Green sandpiper (Tringa ochropus) & $\mathrm{N}^{\mathrm{b}}$ & Eurasia & {$[51]$} \\
Yellow wagtail (Motacilla flava) & $\mathrm{L}^{\mathrm{b}}$ & Eurasia & {$[51]$} \\
White wagtail (Motacilla alba) & $\mathrm{L}^{\mathrm{b}}, \mathrm{N}^{\mathrm{b}}$ & Eurasia & {$[51]$} \\
Reed bunting (Emberiza schoeniclus) & $\mathrm{N}^{\mathrm{b}}$ & Eurasia & {$[51]$} \\
Siberian stonechat (Saxicola maurus) & $\mathrm{L}^{\mathrm{b}}$ & Eurasia & {$[51]$} \\
House sparrow (Passer domesticus) & $\mathrm{L}^{\mathrm{b}}$ & Eurasia & {$[51]$} \\
Tree sparrow (Passer montanus) & $\mathrm{L}^{\mathrm{b}}, \mathrm{N}^{\mathrm{b}}$ & Eurasia & {$[51]$} \\
Pig (Sus scrofa domesticus) & $\mathrm{A}$ & entire D. reticulatus range & {$[22]$} \\
Sheep (Ovis aries) & $\mathrm{A}$ & entire D. reticulatus range & {$[22,61,72,280,283,284,287]$} \\
Goat (Capra aegagrus hircus) & $\mathrm{L}^{\mathrm{b}}, \mathrm{N}^{\mathrm{b}}, \mathrm{A}$ & entire D. reticulatus range & {$[22,59,245,280,283,284,297]$} \\
Cattle (Bos taurus) & $\mathrm{A}$ & entire D. reticulatus range & {$[60,61]$} \\
Horse (Equus caballus) & $\mathrm{A}$ & entire D. reticulatus range & {$[60,61,69,245]$} \\
Donkey (Eq. africanus asinus) & $\mathrm{A}$ & entire D. reticulatus range & {$[10]$} \\
Cat (Felis catus) & $\mathrm{A}$ & entire D. reticulatus range & {$[69,113,280,285,287]$} \\
Dog (Ca. lupus familiaris) & $\mathrm{N}^{\mathrm{b}}, \mathrm{A}$ & entire D. reticulatus range & {$[25,26,60,61,113,245,288,298]$} \\
Human & $\mathrm{N}^{\mathrm{b}}, \mathrm{A}$ & entire D. reticulatus range & {$[4,54-56,59,61-66,69,280,284]$} \\
\hline Li, & & &
\end{tabular}

${ }^{\mathrm{a}} \mathrm{L}$, larva; N, nymph; A, adult

brarely

GIS for the locations with sympatric populations of the two tick species, $D$. reticulatus appeared to be more thermophilic and hygrophilous than I. ricinus while still tolerating large diurnal and seasonal temperature variation. This is not necessarily at variance with the conclusion that $D$. reticulatus is a psychrophilic tick, thriving at relatively low temperatures [76]. Moreover, quantitative evidence suggests that it occurs in places with less precipitation seasonality, near watercourses and water bodies (Široký et al., unpublished data), which further emphasizes its bond to water in the landscape, a feature noted by several observers [22, 42, 76, 77]. Higher tolerance to temperature variation may also explain why it can be encountered along riverbanks and wet grasslands in a cold region of Poland with sunny and hot summers [77] or mountains in Hungary that are often characterised by much higher humidity, especially compared to the lowlands in the Pannonian biogeographical region [34]. The tick's negative host-seeking activity in response to increasing soil temperatures [76] may thus indicate its higher sensitivity to desiccation relative to I. ricinus. Moreover, its larvae are also known to require high relative humidity for successful embryonic development and hatching [78]. Kubelová [35] demonstrated that adult D. reticulatus prefers warmer and wetter sites with greater diurnal and seasonal variation in temperature but with less precipitation seasonality than I. ricinus. A further difference is that I. ricinus seems to be more tolerant of forested habitats than $D$. reticulatus, which prefers open spaces, such as temperate grassland with high moisture conditions, covered by a mosaic of bush and woods [22, 35]. Adults of $D$. reticulatus were shown to survive better in the meadow microclimate than in the forest microhabitat. About $55 \%$ of unengorged females and $58 \%$ of males survived for 399 days in the meadow (including two periods of hibernation), while only $33 \%$ of females and $34 \%$ of males survived in the forest habitat in South Moravia [67].

Dermacentor reticulatus has also been observed in urban areas, e.g. in Grenoble, Munich, Warsaw, Lublin, Kiev, Košice and Budapest [31, 50, 75, 79-86]. Although usually absent in downtown parks $[87,88]$ where larger maintenance hosts are not permanently present, the tick may occur in suburban forests with natural hosts for adults, or even in urbanised areas where dogs (including stray dogs) or horses are common.

\section{Geographical distribution and recent spread}

Dermacentor reticulatus is not a newcomer in Europe. A specimen was collected from a fossil woolly rhino (Coelodonta antiquitatis) from the Pliocene (extending from 5.33 million to 2.58 million years before present) [89]. It is likely that the distribution patterns of the species have changed over this time and more recently man has likely had a profound effect on the distribution of $D$. reticulatus through the introduction of domestic animals and the alteration of the environment. 
Dermacentor reticulatus occurs in the western Palaearctic in regions with generally mild climates. Feider [90] published a map showing patchy distribution of the species in Europe from Germany to Bulgaria and in the western part of the former Soviet Union. Immler [19] also included occurrences in western Europe in his map. The world distribution of $D$. reticulatus was completely described for the first time by Kolonin [91]. Based on this publication, its range extends from northern Portugal and Spain in the west to central Asia in the east, forming a quite narrow and long strip in a westeast orientation, with a separate enclave in the Caucasus [91]. The same author published a map (Fig. 8) on the geographical distribution of this species [92]. Although this represents useful information for world-scale studies, the resolution of the map is too low to be applied for regional epidemiological purposes. Currently, D. reticulatus receives growing public interest because of its expected increasing epidemiological importance. Therefore, the growing number of studies on its biology, vector competence, and spread helps us to better demarcate its distributional range as a result of the growing number of precise localisations.

Dermacentor reticulatus is absent in the dry Mediterranean climate zone, for example in northern Africa, most of Iberian Peninsula, Italy, the Balkans and Turkey; however, it is present in southern France and Portugal. It is also absent in the cold regions in the north of British Islands, the whole of Scandinavia, and the northern

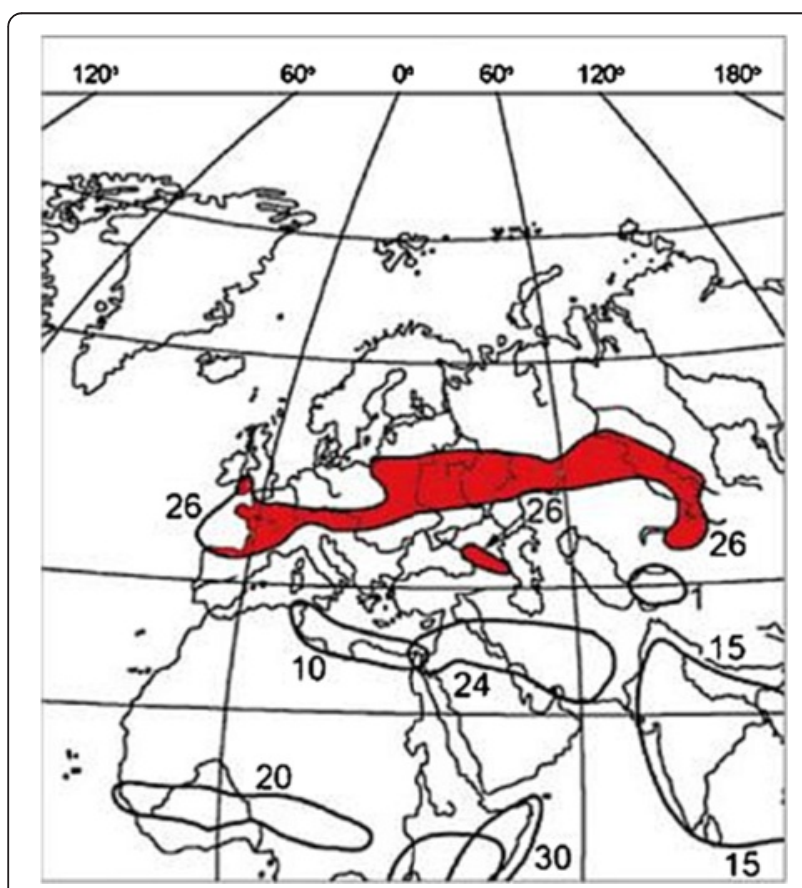

Fig. 8 Geographical distribution of Dermacentor reticulatus (red area, 26) based on Kolonin [92] part of the Baltic region. The distribution pattern of $D$. reticulatus seems to be enigmatic even within this frame, being somehow mosaic or highly focal, following ecological requirements of the species. An on-line available map published by the European Centre for Disease Prevention and Control (ECDC) and Vector-Net project (Fig. 9) shows this pattern, however with some impreciseness, for example false occurrence data in the Czech Republic. There are entire districts in the Czech Republic, which are marked on the map; however, there are no published records of $D$. reticulatus occurrence, e.g. from central and eastern Bohemia, Prague, district Vysočina (Pavel Široký, personal communication). Typical foci have to offer proper microclimate with high relative humidity. Open unploughed habitats with high level of ground water in lowlands or low-altitude hills seem to match best its requirements [22, 32]. In higher mountain regions $D$. reticulatus is absent; however, it can occur in climatically favourable valleys.

During the last decades, the distribution of $D$. reticulatus has considerably expanded in some regions. Large areas of north-western and central Europe, formerly thought to be too cold for its survival and completion of its life-cycle, have experienced a remarkable spread of these ticks in Germany, Poland, Hungary, Slovakia, but also the Netherlands and Belgium (for an excellent review see Rubel et al. [93]). The recent climatic changes have been frequently reported as the predominant driving force [62]. However, anthropogenic impact and socioeconomic changes after the fall of the Iron Curtain should not be overlooked [94]. Human activities, agricultural practices in land use, and particularly travelling with animals and animal trade have changed notably during the last decades. For example, increased availability of unploughed open habitats in central Europe with favourable microclimates has enabled settlement of founder engorged female ticks, probably imported on dogs. International motorway stops are also possible hotspots for $D$. reticulatus introduction (Michiel Wijnveld, personal communication) as many people travel by car with dogs. Reforestations and a steady increase in wildlife populations that are appropriate maintenance hosts for the species, may have contributed to the recent spread [82]. The National Game Management Database estimated a two-fold growth of the red fox population and a 5-10 fold growth of populations of wild boar, red, roe, and fallow deer in Hungary during the last five decades [95]. Similar figures have been published for other European countries $[62,69,82]$. A recent study in Poland demonstrated a dynamic expansion of $D$. reticulatus into areas historically free of this species, and underlined the significance of river valleys as important ecological corridors for wildlife [17]. Populations of dogs, one of the most important maintenance hosts, in and around human dwellings are also increasing. According to 


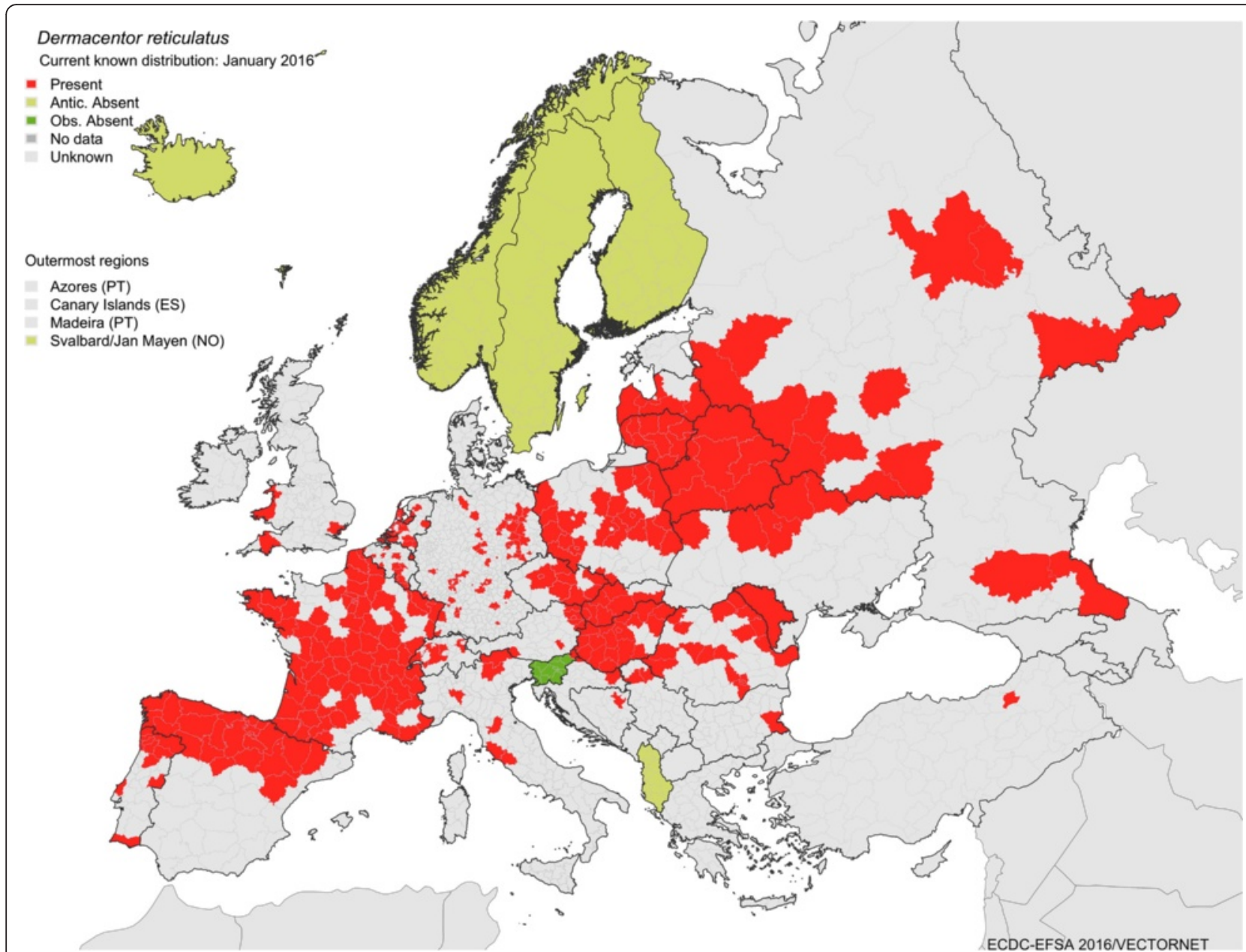

Fig. 9 Geographical distribution of Dermacentor reticulatus based on the European Centre for Disease Prevention and Control (ECDC) and VectorNet project. The map shows the current (January 2016) known distribution of the tick species in Europe at 'regional' administrative level (NUTS3). They are based on published historical data and confirmed data provided by experts from the respective countries as part of the Vector-Net project; see more at: http://ecdc.europa.eu/en/healthtopics/vectors/vector-maps/Pages/VBORNET-maps-tick-species.aspx\#sthash.ca6HyLb6.dpuf

a 2012 estimation [96], 75.3 million dogs live in European households. The number of stray dogs, that are usually more heavily infested, is estimated to be 100 million in Europe [97]. Increased grazing in natural reserves, together with reduction of pesticide usage might well contribute to the growing population of $D$. reticulatus. From 1965 to 1971, the incidence of tick-borne encephalitis in the former Soviet Union decreased by twothirds mainly because of the widespread use of DDT (dichloro-diphenyl-trichloroethane) to kill the vector ticks [98]. With the worldwide abandonment of DDT, the incidence of tick-borne encephalitis cases in the former Soviet Union gradually returned to pre-intervention levels within 20 years [99].

Our knowledge about the tick's recent distribution depends on the availability of published accurate data. Most of the Iberian Peninsula, the western limit of the range of $D$. reticulatus is covered by unsuitably dry habitats; this explains the absence of this tick in most of Portugal and Spain. Nevertheless, reports from northern administrative regions of Portugal (particularly from Montesinho Natural Park, Braganca district) [100] and from northern Spain (particularly in the Basque Country, Cantabria and Navarre) [101, 102] imply that the tick exists in areas with continental climates [103]. Regarding georeferenced data, France could be considered as a distribution centre in the western Europe [93, 103]. Occurrence is reported throughout this country, including the Pyrenean foothills, the Mediterranean zone, and Biscay areas (Fig. 10) [104-106]. Data on D. reticulatus distribution are missing from northern France, particularly along the shore of the English Channel [103]. However, in Belgium and particularly in the Netherlands, the species is reported throughout both countries, including coastal lowlands along the North Sea [69, 107-110]. Dermacentor reticulatus is absent from the Alps; however, it penetrates 


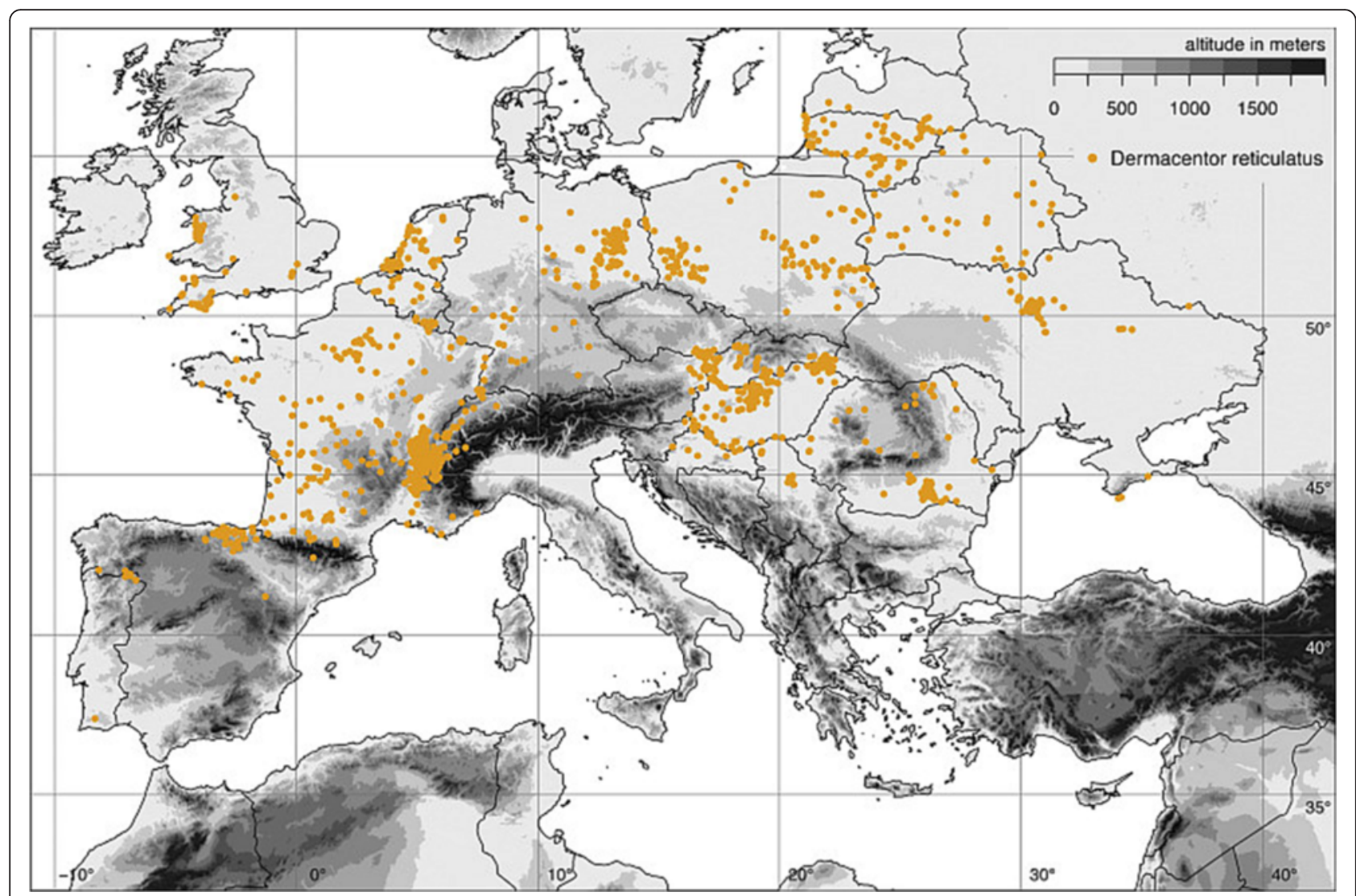

Fig. 10 Map of georeferenced Dermacentor reticulatus locations based on Rubel et al. [93]

deeply into warmer valleys both in France and western Switzerland, where its occurrence is known for many decades [31, 111-113]. The tick's north-western limit is located in the United Kingdom. Dermacentor reticulatus has been found here for over 100 years and is considered to be endemic, with an apparent recent expansion of its range [114]. Its distribution is restricted particularly to western Wales, Devon and parts of Essex. The tick is apparently absent in Ireland (Fig. 10) [5, 115].

Although central Europe was thought to be free of this species [82] from the Alps in the south, through eastern Switzerland, most of Austria, Slovenia, Czech Republic, Poland, and Germany in the north (nevertheless, without any proof provided by population genetic studies using adequate markers), intensive geographical spread was documented during the last decades in this region. The tick became common within the Pannonian iogeographical region, not only in Hungary $[25,34$, 116-118] but also in neighbouring Slovakia [22, 83, 119-121], eastern Austria [122-124] and adjacent areas of the Czech Republic [22, 32, 76, 119, 125]. Focal distribution of $D$. reticulatus has been reported also throughout Germany $[62,126,127]$ and recently from Poland [14, 15, 17, 60, 77, 80, 84, 128-131]. Based on this trend, the central European gap in the geographical distribution of the tick may disappear very soon (Fig. 10).

The tick's range around the Pannonian biogeographical region includes eastern Slovenia [93, 132], northern Croatia [133, 134], and northern Serbia [135, 136]. Ticks have also been occasionally reported from dogs in Bosnia and Herzegovina [133, 137]. In the eastern Balkans, Romania is another example of a rapidly growing number of records of $D$. reticulatus [61, 138, 139]. The tick exhibits an uninterrupted distribution from eastern Poland to Belarus and Baltic countries. Reported distribution is quite even, without remarkable foci throughout Belarus [140, 141], while a bit more clustered in Lithuania and southern Latvia [142, 143]. Local data is absent from the area eastwards of Romania [93], however, we can expect its occurrence in western regions of Ukraine and probably also in Moldavia. Detailed distribution data on $D$. reticulatus have recently been published for areas of central and north-eastern Ukraine, as well as for the Crimean Peninsula (Fig. 10) [50, 85, 93, 144].

The eastern part of $D$. reticulatus distribution was demarcated for the first time by Pomerantsev [71]. The species occurred within the USSR, with its northern limits in the regions of Smolensk, Moscow, Ivanovo, Ryazan, further through Gorki and Kamyshlov area of 
Sverdlovsk District, Tyumen, Omsk, and Novosibirsk districts, eastwards up to Kansk in Krasnojarsk District. The southern limits extend to the southern Crimean Peninsula, Ciscaucasia and Transcaucasia, eastern Kazakhstan, Kirgizstan, and western Altai Mountains [71]. A similar but more roughly estimated range was depicted in Kolonin [91, 92] (Fig. 8) [91]. Filippova [145] described the eastern part of $D$. reticulatus distribution showing that its occurrence has a disjunctive character, being spread mostly through the southern Taiga in zones of mixed or deciduous forests, from the Baltic region of Kaliningrad, south of Saint Petersburg region, up to the upper reaches of Yenisei River. The species also occurs in the steppe zone along river valleys. Southern limits were established to be in south-western Moldavia, the mountains of the Crimean Peninsula, both Greater and Lesser Caucasus, and northern Kazakhstan. Further, the tick is known from the foothills of Kopet-Dag, Altai, and Tian-Shan Mountains [145]. Recently, the tick and canine babesiosis has been reported from three dogs in the eastern Anatolia region of Turkey [146]. Some areas of the Russian part of the range of $D$. reticulatus have recently been subjected to intensive research resulting in additional distribution data; nevertheless, the exact location, with coordinates, is usually missing [29, 147-151]. China (provinces Xinjiang and even Shaanxi and Shanxi) is considered to be the southeastern limit of its distribution [152].

\section{Veterinary health importance \\ Babesia canis}

Considering geographical distribution, economic and health impact, Babesia canis is undoubtedly the most significant pathogen transmitted to animals by $D$. reticulatus. This piroplasmid apicomplexan parasite is able to invade ovaries of female ticks and is transmitted transovarially to the next generation of larvae [153]. Together with transstadial transmission, this feature enables $D$. reticulatus populations to function as a reservoir in addition to their vector role, enabling maintenance of $B$. canis locally for several tick generations even without a vertebrate reservoir host [154]. A further consequence of the highly specialised $B$. canis life-cycle is that, the key driver of genetic variability of this emerging canine pathogen, the piroplasmid parasite's exchange of genetic material, occurs within $D$. reticulatus [153].

As reviewed by Matijatko et al [155], the considerable differences in the clinical disease manifestations may also reflect the above mentioned genetic variability leading to different $B$. canis strains. Uncomplicated canine babesiosis (with a mortality rate $<5 \%$ ) has been suggested to be a consequence of anaemia resulting from haemolysis, whereas complicated canine babesiosis may be a consequence of the development of systemic inflammatory response syndrome (SIRS) and multiple organ dysfunction syndrome (MODS). Clinical signs of uncomplicated babesiosis include pale mucous membranes, fever, anorexia, depression, splenomegaly, hypotension and water hammer pulse. Clinical manifestations of the complicated form of babesiosis (mortality rates of up to $20 \%$ ) depend on the particular complications that develop, such as cerebral babesiosis, shock, rhabdomyolysis, acute renal failure, acute respiratory distress syndrome, acute liver dysfunction and acute pancreatitis [155]. A recent study [156] classified $B$. canis strains based on major merozoite surface antigens coding DNA (bc28.1 gene). However, the recognised two groups, Bc28.1-A strains (relatively virulent or mild) and Bc28.1-B (virulent), showed great variation in their geographical distribution. The authors hypothesised that the distribution of $B$. canis genotypes might be dependent on the presence of genetically different $D$. reticulatus strains in certain geographical areas, but this remains to be demonstrated [156]. Such genetic variability and antigenic variation are not only important for the survival of $B$. canis in their vertebrate hosts but has implications for vaccine development strategies. The capacity of $B$. canis to change the antigenic make-up of its merozoite surface is one of the major impediments of vaccine development, and has been suggested as a possible explanation for the limited efficacy of a commercially available vaccine in the field $[156,157]$.

The wide geographic distribution of $B$. canis is in line with that of its vector, i. e. from western Europe to Siberia $[155,158]$. Based on molecular screening of field collected ticks, the prevalence of $B$. canis in adult $D$. reticulatus ticks varies from $0 \%(n=197)$ in studies conducted for instance in Germany [159] or Belarus $(n=142)$ [141] to $0.7 \%(n=582)$ in eastern Poland, $1.64 \%(n=855)$ in the Netherlands [69], $2.3 \%(n=$ $1,205)$ in south-western Slovakia [120], $3.41 \%(n=205)$ in Ukraine [144], $4.18 \%(n=2,585)$ in Poland [15] to exceptionally as high as $14.7 \%(n=327)$ in eastern Slovakia [120] and $14.8 \%(n=233)$ in southern Poland [15].

The natural cycle of $B$. canis is enigmatic since it has no known wildlife reservoir host. Studies performed on candidate reservoir wild canids did not find evidence for a wild-living host capable of maintaining the parasites. Reports from Italy (205 red foxes, seven grey wolves) [160], Hungary (404 red foxes) [161], Austria (36 red foxes) [162] and Slovakia (nine red foxes) [163] found no $B$. canis despite the large number of wildlife samples screened. Single foxes were found to have B. canis infection based on PCR in one of 91 samples in Portugal [164] and one of 73 samples in Bosnia and Herzegovina [165]. This is not surprising as D. reticulatus occurs on foxes and can transmit the parasite to this host; however, based on the rarity of infection, the red fox can be excluded as a natural reservoir. Another candidate, the golden jackal (Canis aureus) which has spread into new 
areas recently, has also not been found to be infected in the limited samples tested so far [52, 124, 166]. Captive grey wolves were shown to be susceptible to $B$. canis infection which can be even lethal for them [167], but no evidence exists on their potential role as asymptomatic carriers. There is, therefore, no indication that wolves are capable of playing a role in the natural cycle of this piroplasm. As other D. reticulatus hosts were not so far shown to be frequently or at all infected with $B$. canis, the only remaining plausible candidate to fill the gap in the reservoir position of the transmission cycle is the domesticated dog. Our hypothesis is that B. canis can persist in some dogs asymptomatically for a long time, so that when infested by $D$. reticulatus serve as a source of the parasite to the feeding ticks. There is empirical evidence for subclinical canine babesiosis, e.g. from France [168, 169], Slovakia [170], Poland [171] and Turkey [172]. However, in order to establish the reservoir role of dogs, experimental infections using xenodiagnostic $D$. reticulatus ticks have to be performed. For the closely related species, Babesia caballi, long-term asymptomatic carrier horses have already been reported [173-176].

There are several implications of the probable reservoir role of dogs in the B. canis cycle. First, asymptomatic dogs may be able to infect puppies vertically as shown for Theileria equi in horses [177]. Although vertical transmission appears to be rare in Babesia (sensu stricto), it has been described for $B$. divergens [178]. A recent observation confirmed vertical transmission of $B$. canis from female dogs to puppies [179]. Second, this would provide a sound explanation for the recent geographical spread of canine babesiosis $[26,69,120,180]$. Based on the relatively low prevalence of the pathogen in field-collected ticks, it is more probable to import a dog with either symptomatic or asymptomatic $B$. canis infection into a new area, than importing infected $D$. reticulatus specimens. When the piroplasm has already been imported with dogs into a new area, the local $D$. reticulatus population is likely to become infected and can sustain $B$. canis for several years by transovarial and transstadial transmission, leading to a detectable presence in the local tick population. Consequently, dogs are not necessarily required for the short term maintenance of infected ticks. In line with this, in many new foci, e.g. in the Netherlands, Belgium, Norway, Switzerland, Hungary, Slovakia, Germany, canine babesiosis was observed first without the presence of infected ticks or even the tick itself in the area $[107,112$, $120,180-185]$. Finally, we assume that in evolutionary terms $B$. canis originated in domesticated dogs (or their ancestors) and not in a related wildlife reservoir host.

\section{Babesia caballi and Theileria equi}

Equine piroplasmosis caused by B. caballi and T. equi is the most prevalent tick-borne disease in equids (horses, mules, donkeys, zebras) in certain areas of the world and besides causing important economic losses it also leads to movement restrictions [173]. Worldwide, cases are tracked by the World Organisation for Animal Health (OIE: Office International des Epizooties) (http://www.oie.int/). According to this, most of the equid-inhabited regions of the world are considered endemic for infection and disease. Cases are consistently reported from Central and South America, Cuba, Europe, Asia and Africa. In non-endemic countries such as Australia, Canada, Great Britain, Ireland, Japan, New Zealand, and until recently, the United States, only seronegative horses are allowed to be imported to prevent the introduction of carrier animals [186]. Seropositive horses cannot cross borders to compete in races or horse shows, be used for breeding purposes, or be sold abroad [187]. These two parasites have biological differences but cause similar pathology and have similar vector relationships. Acute disease is characterised by fever, malaise and reduced appetite, increased pulse rates and respiration, anorexia, constipation followed by diarrhoea, tachycardia, petechiae, splenomegaly, thrombocytopenia, and haemolytic anaemia leading to haemoglobinuria and icterus $[174,186]$. Horses that recover from acute disease remain persistently infected carriers without overt signs of disease and can be reservoirs for transmission of these protozoan pathogens by vector ticks. Parasitaemia is often too low to be detected on blood smears, but infected animals can be identified by serology or polymerase chain reaction (PCR). Similarly to B. canis, sexual-stage development (resulting in genetically new offspring) is completed in ticks for both $T$. equi and $B$. caballi $[153,186]$.

Dermacentor reticulatus is not the only vector species for B. caballi, several members of the genera Hyalomma, Rhipicephalus, Dermacentor and Haemaphysalis are able to transmit it [174]. The life-cycle of $B$. caballi involves transovarial transmission from females via eggs to hatching larvae. Consequently, $B$. caballi can be sustained for several tick generations similarly to $B$. canis. As $D$. reticulatus is a common ectoparasite of horses $[60,69,131]$ and acts as vector of this parasite with transovarial and transstadial transmission [186], it can often infect them with $B$. caballi. This can lead to relatively high seroprevalences of B. caballi in endemic areas [173]. Within the world domestic equine population (approximately 112 million in 2013), rates of infection in endemic regions are often above $60 \%$, and in some regions more than $90 \%$ of the animals are infected with one or both parasites [186]. Most of these are persistently infected without any sign of clinical disease. As suspected for B. canis, it has been shown for B. caballi, that the basis for its spread is movement of these clinically healthy carrier animals into regions with competent tick vectors, where they can be a 
source of infection for the naïve horse populations [186]. Once recovered from an acute episode, horses were reported to remain carriers of $B$. caballi for up to four years [174].

Theileria equi, previously considered a species of Babesia, was reclassified [188] because of the absence of transovarial transmission in the vector and because sporozoites do not infect red blood cells, but first penetrate a lymphocyte (or macrophage) where they develop into schizonts [173]. Infections with T. equi (which is more frequently reported [189]), are usually more severe than those with $B$. caballi but it is impossible to distinguish between the two parasitic infections based on clinical signs alone. Equine theileriosis differs from equine babesiosis also in the length of asymptomatic carrier status: once infected, horses remain carriers of $T$. equi for life [174] thereby serving as a continuous source of infection for vector ticks. Similarly to B. caballi, T. equi can be transmitted by several tick species [186]. The vector competence of $D$. reticulatus for $T$. equi, with experimental evidence of transstadial infection, has been confirmed [190, 191]. The worldwide spread T. equi is more prevalent than B. caballi [186]; this reflects differences in their vector biology as well as differences in persistence of the parasites in the equine host mentioned above.

\section{Anaplasma marginale}

Bovine anaplasmosis is an important tick-borne disease of domesticated ruminants worldwide caused by infection of cattle with the obligate intraerythrocytic bacterium Anaplasma marginale of the family Anaplasmataceae, order Rickettsiales [192]. The acute phase of bovine anaplasmosis is characterised by anaemia, icterus, weight loss, fever, abortion, decreased milk production, and often results in death [193]. Animals surviving the acute phase develop a lifelong persistent infection and can serve as reservoirs for mechanical transmission and biological transmission by ticks [194].

Mechanical transmission occurs in various ways: blood-contaminated fomites, including hypodermic needles, castration instruments, ear tagging devices, tattooing instruments, and dehorning saws or by bloodcontaminated mouthparts of biting flies [193-195]. Biological transmission is by ticks and over 20 species have been incriminated as vectors worldwide. Recently, an experimental study has shown that $D$. reticulatus can also transmit A. marginale intrastadially [194]. This route of pathogen transmission is enhanced by the extended stay of male $D$. reticulatus ticks on the host and their intermittent feeding behaviour (as detailed above in the section "Life-cycle and ecology"). Males can feed and transmit $A$. marginale multiple times as they transfer among cattle. Indeed $D$. reticulatus can be the main vector of $A$. marginale as shown in a study performed on ticks removed from cattle in Hungary, where $D$. reticulatus, rather than the other three tick species were involved in A. marginale transmission [196]. The main route for tick-transmitted bovine anaplasmosis is probably the intrastadial infection by male $D$. reticulatus, since immatures of this tick species usually do not feed on cattle, thus cannot provide transstadial infection for the adult ticks.

\section{Public health importance}

Dermacentor reticulatus has been reported parasitising humans in Russia, Austria, the United Kingdom, France, Hungary and Spain $[63,64,74]$ but bites humans much less frequently than I. ricinus or I. persulcatus $[63,197]$. It is considered to be the most common [32, 60,69] or second most common [51, 116] species in many areas and in western Siberia, this species was the second most common tick found on humans after I. persulcatus [56]. Based on this, the direct impact of $D$. reticulatus on public health, and its relative contribution to the disease burden caused by vector-borne diseases, is relatively small in many regions of Eurasia, but can be substantial in endemic areas and should definitely not be ignored. An example of emergence as a result of efficient transport by human travel is shown by a recent paper reporting the detection of a male $D$. reticulatus on a patient in Irkutsk (eastern Siberia) who acquired the tick in the Tula region (western Russia), 5,000 km to the west [198]. Even longer journeys have already been made by this species, because its presence was reported on horses transported to the USA in the 1960s, 1970s and 1980s from France [199].

Dermacentor reticulatus transmits a particular set of pathogens to humans, which might cause serious disease if not diagnosed and treated appropriately in a timely manner. Awareness by medical doctors of the potential public health risk of this tick in their patient population, and availability of supportive laboratory diagnoses are essential. The pathogens (and associated diseases) that can be transmitted by $D$. reticulatus are briefly reviewed below. The 40 microbial agents that have been detected in this tick are listed, though there is uncertainty about its vector role for some of them (Table 2). It should be noted that molecular techniques have weaknesses, including the inability to distinguish living from dead microorganisms and the risk exists of contamination or PCR artefacts from various sources. Whether D. reticulatus can transmit these pathogens should first be established in vector-competence experiments. The unknown relevance of molecular detection of pathogens is exemplified by a study performed on field-collected adult $D$. reticulatus in Poland, where $2.5 \%$ of the 468 ticks were positive for Babesia microti [200]. The authors used 
Table 2 Pathogens detected in Dermacentor reticulatus

\begin{tabular}{|c|c|c|c|c|c|c|}
\hline Status & Pathogen & Disease & Region & Relevance & Note & References \\
\hline \multirow[t]{8}{*}{ Vector } & $\begin{array}{l}\text { Omsk } \\
\text { haemorrhagic } \\
\text { fever virus }\end{array}$ & $\begin{array}{l}\text { Omsk } \\
\text { haemorrhagic } \\
\text { fever }\end{array}$ & $\begin{array}{l}\text { Western } \\
\text { Siberia }\end{array}$ & $\mathrm{PH}$ & & [207] \\
\hline & $\begin{array}{l}\text { Tick-borne } \\
\text { encephalitis } \\
\text { virus }\end{array}$ & $\begin{array}{l}\text { Tick-borne } \\
\text { encephalitis }\end{array}$ & Eurasia & $\mathrm{PH}$ & & {$[80,149,228,299]$} \\
\hline & Rickettsia raoultii & TIBOLA/DEBONEL & Eurasia & $\mathrm{PH}$ & & $\begin{array}{l}{[15,62,64,107,126,} \\
141,159,235,238, \\
245,247-249,300- \\
303]\end{array}$ \\
\hline & Rickettsia slovaca & TIBOLA/DEBONEL & Eurasia & $\mathrm{PH}$ & & $\begin{array}{l}{[64,238,245,300,} \\
304]\end{array}$ \\
\hline & $\begin{array}{l}\text { Anaplasma } \\
\text { marginale }\end{array}$ & $\begin{array}{l}\text { Bovine } \\
\text { anaplasmosis }\end{array}$ & France & VET & $\begin{array}{l}\text { Disseminated infection } \\
\text { and mechanical } \\
\text { (surgery) calf to calf } \\
\text { transmission }\end{array}$ & {$[104,194,196]$} \\
\hline & Babesia canis & Canine babesiosis & Eurasia & VET & & $\begin{array}{l}{[69,112,123,144,} \\
180,300,305]\end{array}$ \\
\hline & Babesia caballi & Equine babesiosis & $\begin{array}{l}\text { Southern } \\
\text { Europe }\end{array}$ & VET & & [69] \\
\hline & Theileria equi & Equine theileriosis & Eurasia & VET & & {$[188,306,307]$} \\
\hline \multirow{15}{*}{$\begin{array}{l}\text { Carrier: found in questing or fed } \\
\text { ticks or used in experimental } \\
\text { infection studies (with unknown } \\
\text { vector role) }\end{array}$} & Kemerovo virus & $\begin{array}{l}\text { Kemerovo tick } \\
\text { fever }\end{array}$ & $\begin{array}{l}\text { Western } \\
\text { Siberia }\end{array}$ & $\mathrm{PH}$ & & [148] \\
\hline & $\begin{array}{l}\text { Bluetongue virus } \\
\text { (BTV-8) }\end{array}$ & $\begin{array}{l}\text { Bluetongue } \\
\text { disease }\end{array}$ & n.a. & $\mathrm{PH}$ & $\begin{array}{l}\text { Disseminated infection } \\
\text { but no transstadial or } \\
\text { transovarial infection }\end{array}$ & [308] \\
\hline & Palma virus & $?$ & n.a. & $?$ & $\begin{array}{l}\text { transmission by co- } \\
\text { feeding on laboratory } \\
\text { mice }\end{array}$ & [309] \\
\hline & $\begin{array}{l}\text { Murid } \\
\text { herpesvirus } 4\end{array}$ & Not known & Slovakia & $?$ & & [310] \\
\hline & $\begin{array}{l}\text { Rickettsia } \\
\text { helvetica }\end{array}$ & $\begin{array}{l}\text { Aneruptive fever, } \\
\text { endocarditis }\end{array}$ & Eurasia & $\mathrm{PH}$ & & {$[115,141,250]$} \\
\hline & $\begin{array}{l}\text { Rickettsia sibirica } \\
\text { sibirica }\end{array}$ & $\begin{array}{l}\text { Siberian tick } \\
\text { typhus }\end{array}$ & Asia & $\mathrm{PH}$ & & {$[311,312]$} \\
\hline & $\begin{array}{l}\text { Anaplasma } \\
\text { phagocytophilum }\end{array}$ & $\begin{array}{l}\text { Human, canine } \\
\text { and equine } \\
\text { granulocytic } \\
\text { anaplasmosis }\end{array}$ & Eurasia & $\mathrm{PH}+\mathrm{VET}$ & & $\begin{array}{l}{[104,144,247,313,} \\
314]\end{array}$ \\
\hline & $\begin{array}{l}\text { Borrelia } \\
\text { burgdorferi (s.s.) }\end{array}$ & Lyme borreliosis & Eurasia & $\mathrm{PH}$ & & [141] \\
\hline & $\begin{array}{l}\text { Borrelia } \\
\text { burgdorferi (s.l.) }\end{array}$ & Lyme borreliosis & Eurasia & $\mathrm{PH}$ & & $\begin{array}{l}{[104,107,141,315,} \\
316]\end{array}$ \\
\hline & Borrelia afzelii & Lyme borreliosis & Eurasia & $\mathrm{PH}$ & $\begin{array}{l}\text { Also detected in } \\
\text { engorged larvae } \\
\text { removed from } \\
\text { uninfected mice }\end{array}$ & {$[15,141,206]$} \\
\hline & $\begin{array}{l}\text { Borrelia } \\
\text { valaisiana }\end{array}$ & Lyme borreliosis & Eurasia & $\mathrm{PH}$ & & [141] \\
\hline & Borrelia garinii & Lyme borreliosis & Eurasia & $\mathrm{PH}$ & & [158] \\
\hline & Coxiella burneii & Q-fever & Eurasia & $\mathrm{PH}$ & & {$[104,317]$} \\
\hline & $\begin{array}{l}\text { Francisella } \\
\text { tularensis ssp. } \\
\text { holarctica }\end{array}$ & Tularemia & Eurasia & $\mathrm{PH}$ & & {$[200,318,319]$} \\
\hline & $\begin{array}{l}\text { Francisella } \\
\text { philomiragia }\end{array}$ & & Eurasia & $\mathrm{PH}+\mathrm{VET}$ & Not tick-transmitted & [104] \\
\hline
\end{tabular}


Table 2 Pathogens detected in Dermacentor reticulatus (Continued)

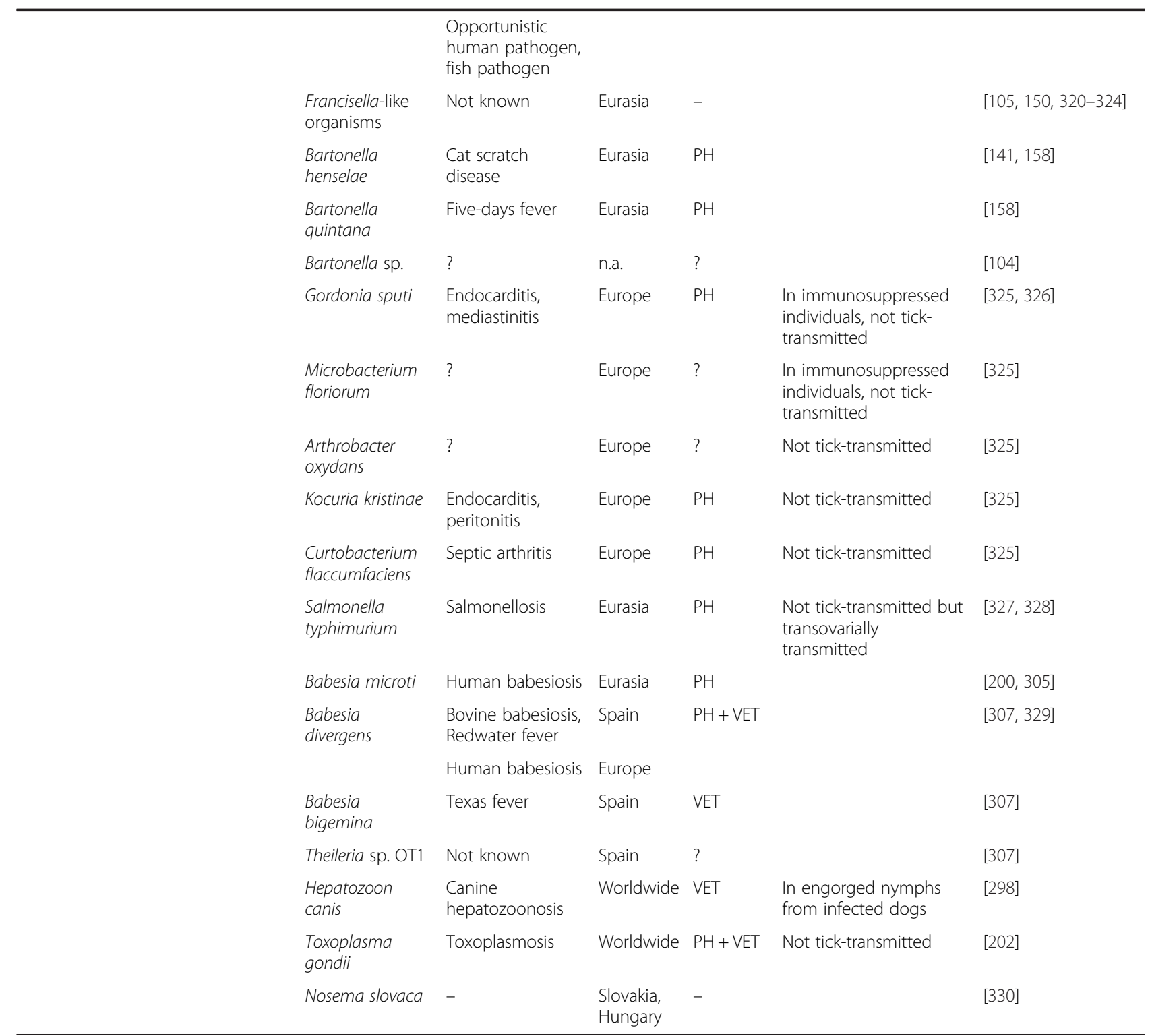

Abbreviations: $P H$ public health; VET. veterinary; n.a. not applicable

amplified rDNA fragments that were only 238 base pairs long and the similarity of their PCR products was only 97-99\% to known B. microti sequences. Based on these findings, no conclusions should be drawn about the potential vector role or the public health relevance of $D$. reticulatus in transmission of $B$. microti. Czech scientists cultured an additional 38 bacterial strains with mainly unknown medical or veterinary importance from field-collected D. reticulatus [201] that are not listed in our table. One of the latest additions to the long list of microbes is Toxoplasma gondii [202], a parasite with a life-cycle involving a multitude of hosts but surely not specialised for tick transmission.
We would like to call attention also to the possible indirect role of this tick species in pathogen cycles. As has been shown for A. phagocytophilum and Babesia microti transmitted by nidicolous Ixodes trianguliceps to rodents [203, 204] and B. burgdorferi (sensu lato) (s.l.) transmitted by $I$. hexagonus to hedgehogs [205], immatures of D. reticulatus are probably also involved in the endophilic pathogen cycles of disease agents [206]. Similarly to the recently published endophilic cycle of $B$. afzelii maintained by the nidicolous $I$. acuminatus on rodents and by $I$. ricinus in an exophilic cycle [206], D. reticulatus immatures may also maintain pathogens that could be transmitted to humans or domesticated animals by adults of the same 
species or by other (exophilic) ticks. Exploration of the endophilic pathogen cycles associated with $D$. reticulatus is therefore of fundamental importance.

\section{Omsk haemorrhagic fever virus (OHFV)}

The first cases of Omsk haemorrhagic fever (OHF) were diagnosed in the 1940s in four adjacent Provinces of Russia: Omsk, Novosibirsk, Kurgan, and Tyumen. Between 1946 and 1958, more than 1,000 cases of OHF were diagnosed, after which the incidence decreased. Although OHF cases have not been officially recorded, an increase of $\mathrm{OHF}$ in endemic areas has been apparent since 1988. In about $80 \%$ of cases, OHF infection results in mild flu-like, symptoms. Common symptoms include fever, headache, myalgia, cough, bradycardia, dehydration, hypotension, and gastrointestinal symptoms [207]. Such OHF cases may be easily missed or misdiagnosed [208]. The onset of OHF is sudden, with fever lasting five to 12 days. Approximately 30 to $50 \%$ of patients experience a second febrile phase. During the second phase, patients can develop meningeal signs, but neurological involvement has not been reported. The haemorrhagic manifestations of OHF are typically nosebleeds, bleeding gums, vomiting of blood, blood in the lungs and non-menstrual bleeding of the uterus. Recovery from OHF is generally slow and its case-fatality rate varies from 0.5 to $2.5 \%$ [207].

Omsk haemorrhagic fever virus (OHFV) belongs to the tick-borne virus group, genus Flavivirus, family Flaviviridae. It is phylogenetically closely related to tick-borne encephalitis virus (TBEV), and to a lesser extent to Kyasanur forest disease virus (KFDV) and Alkhurma haemorrhagic fever virus (AHFV). It is remarkable that TBEV has spread from western Europe to Japan [209], whereas the circulation of OHFV remained restricted within four Siberian provinces during hundreds of years of evolution [210]. Humans can become infected through tick bites, with $D$. reticulatus being the main vector, or through contact with body fluids of infected animals and environmental samples. The sylvatic cycle of OHFV appears to include several vertebrates, particularly water voles (Arvicola amphibius, formerly $A$. terrestris) and narrow-headed voles (Microtus gregalis) and the principal vector is $D$. reticulatus which is able to transmit the virus transovarially [7]. Vole populations are cyclic, and expansion of the virus-infected tick population coincides with increases in vole populations [211]. The prevalence of ticks infected with OHF virus corresponds to the density of ticks in a given focus. During the epidemic period (1945-1949) of OHF in the lake region of Omsk district, the density of $D$. reticulatus was ten times greater than during the non-epidemic period of 1959 to 1962 . In the former period, all cattle in the region were infested, and larvae and nymphs were mainly found on voles, particularly narrow-headed voles, with the prevalence of infected ticks at $6 \%$. In contrast, only 0.1-0.9\% of ticks was infected during the non-epidemic period [212].

The disease emerged in Omsk Province shortly after the introduction of the North American muskrat (Ondatra zibethicus), when more than 4,000 muskrats were released into the wild. This muskrat species turned out to be highly susceptible to OHFV infection. Many deadly epizootics in muskrats have been recorded since the 1940s. Although OHFV is transmitted mainly by $D$. reticulatus, occupational and recreational activities such as hunting, trapping or skinning muskrats may have also caused OHF outbreaks $[208,213]$.

Two important unresolved issues remain: (i) What caused the outbreak in the 1940s? Is it really a new pathogen, having sprung up 70 years ago, or an indigenous arbovirus re-emerging as a consequence of new ecological conditions? (ii) What limits the further geographical spread of OHFV? The main vector, $D$. reticulatus, as well as its main vertebrate hosts, the water vole and the muskrat, are widely distributed over northern Eurasia. Perhaps OHFV transmission is only possible in specific climatic conditions, where co-feeding of nymphal and larval stages of $D$. reticulatus occur, which is regarded as a rare event. Another possibility is that other tick-borne flaviviruses, notably TBEV, compete with OHFV. The latter is not unlikely as TBEV protective antibodies cross-react with and neutralize OHFV $[214,215]$.

\section{Tick-borne encephalitis virus (TBEV)}

Tick-borne encephalitis (TBE) is a common and occasionally fatal tick-transmitted disease in central and eastern Europe and Russia [216, 217]. It is an infection of the central nervous system caused by the tick-borne encephalitis virus (TBEV). The clinical aspects and epidemiology of TBE, as well the ecological aspects of TBEV have been reviewed elsewhere [218-220], and therefore, they are only mentioned here briefly. The clinical spectrum of the disease ranges from mild meningitis to severe meningoencephalitis with or without paralysis and death. A postencephalitic syndrome, causing long-lasting morbidity, may occur in patients after acute tick-borne encephalitis. The clinical course and outcome vary by subtype of tickborne encephalitis virus, age of patients, and host genetic factors [221]. TBEV is transmitted to humans predominantly by $I$. ricinus and $I$. persulcatus and, to a far lesser extent, by $D$. reticulatus. During the last few decades the incidence of the disease has increased and poses a growing health problem in almost all endemic European and Asian countries. Vaccination can effectively prevent the disease and is suggested for persons living in or visiting tickborne encephalitis endemic areas [222].

Transovarial transmission of the TBEV via the eggs from an infected adult female tick to its offspring has been 
documented, but seems to be rare and its importance to the maintenance of the virus in nature is considered to be rather low [223]. Compared to, for example, the highly efficient (94-100 \%) filial infection rate of Rickettsia conorii in Rhipicephalus sanguineus [224], the proportion of larvae transovarially infected with TBEV is low $(<5 \%)$ [225]. Although rodents and large mammals (e.g. deer, cattle) can be infected and become viraemic, systemic infection is not necessary and of little importance for viral transmission [226]. TBEV can be transmitted from infected to non-infected ticks when they co-feed in close proximity on the same host [227]. For successful co-feeding transmission nymphs and larvae should feed simultaneously on the same host. It is unlikely that $D$. reticulatus can maintain TBEV in enzootic cycles in Europe as there is only a very short interval for the possibility of co-feeding larvae and nymphs [6] (see also section "Life-cycle and ecology").

The potential role of $D$. reticulatus in the maintenance and circulation of TBEV and a link with cattle as potential reservoir hosts has been suggested in recent studies from Poland [80, 228]. Mierzejewska et al. [228] recently reported high prevalence of TBEV (7.6 \%) in D. reticulatus that is consistent with the results $(10.8 \%)$ obtained by a previous survey. Interestingly, prevalence of TBEV in $D$. reticulatus may be up to ten times higher than in $I$. ricinus (7-11 \% vs 0-1.2 \%) [228, 229]. Cattle serve frequently as hosts for D. reticulatus [10] and the dominance of this tick over I. ricinus on bovine hosts in regions endemic for $D$. reticulatus has been reported recently [60]. According to these studies, grazing cattle may play a dual role; they serve as an easily available source of blood meals compared to wild animals, thus supporting the expansion of $D$. reticulatus and might act as a reservoir for the TBEV. Transmission of TBEV to cattle may be followed by transfer of this virus to humans via non- pasteurised milk or other dairy products from infected animals (mainly goats, sheep and cows) [94]. Milk-borne TBE outbreaks or single cases have been reported from Russia, the former Czechoslovakia, Hungary, Austria and Germany [220, 230, 231]. A recent study confirmed that TBEV is transmitted transovarially in $D$. reticulatus [232]. However, the role of $D$. reticulatus compared to that of $I$. ricinus and I. persulcatus remains secondary or of local importance in TBEV transmission cycle.

\section{Rickettsia slovaca and Rickettsia raoultii}

The two spotted fever rickettsiae transmitted by $D$. reticulatus are Rickettsia slovaca and $R$. raoultii. They are the causative agents of the syndromes known as Tick-borne lymphadenopathy (TIBOLA) [233, 234], recently also referred to as Dermacentor-borne-necrosiserythema-lymphadenopathy (DEBONEL), and Scalp eschar neck lymphadenopathy (SENLAT) [235, 236]. Tick- borne lymphadenopathy is the most common tickborne rickettsiosis in Europe after Mediterranean spotted fever and occurs in Spain, France, Portugal, Italy, Hungary, Germany, Bulgaria and Poland [235, 236]. Although originally only $D$. marginatus was implicated as a vector, recent studies clarified the role of $D$. reticulatus having a similarly important role in the transmission of rickettsiae causing TIBOLA [64, 236]. The role of male $D$. reticulatus ticks in the transmission of $R$. raoultii has also been shown [64]. In earlier reports, only $R$. slovaca was found to be the main agent of TIBOLA [237, 238], however it seems that $R$. raoultii can be an important or even frequent pathogen in this emerging infection [64].

Clinical manifestations include an eschar at the site of the tick attachment (nearly always on the scalp) surrounded by an erythema and regional/painful lymphadenopathies. If the tick bite is on the scalp, patients may suffer from facial oedema. In rare cases when the tick bite is located elsewhere than the scalp, an erythema with an eschar at the site of the tick-bite usually appears. Reports about these syndromes are rare, but have occurred throughout Europe [235, 239]. Little is known about the enzootic cycles of $R$. slovaca and $R$. raoultii. Probably co-feeding transmission between ticks from the same generation in combination with efficient transovarial transmission may suffice to sustain the enzootic cycle of tick-borne rickettsiae [240]. It is unclear which vertebrate hosts are involved in the amplification of Rickettsia-infected ticks, as systemic infection of vertebrate hosts is rarely reported. Contact with horses was found to be an important risk factor for acquiring TIBOLA, however it is not known whether horses might be reservoirs or whether they contribute indirectly with the high number of Dermacentor ticks feeding on them [65]. A recent study found $R$. slovaca by PCR in Apodemus spp. mice ear biopsies [241]. Another member of the spotted fever group, $R$. massiliae was shown to be transmitted by co-feeding (and possibly mating) between Rhipicephalus turanicus ticks [242]. The efficiency of co-feeding transmission of $R$. conori between $R h$. sanguineus feeding on naïve dogs is estimated to be between $92-100 \%$, whereas for ticks on seropositive dogs the estimate was between 8-28.5\% transmission via co-feeding [242]. Accordingly, a relatively high prevalence of $R$. raoultii was observed in questing $D$. reticulatus adults in Austria (minimum prevalence of $14.9 \%$ ) [243], Romania (18 \%) [244], Slovakia (22.3-27 \%) [245], UK (27 \%) [246], the Baltic countries (1-36.9\%) [247], Germany (44 \%) [126], Poland (44-53 \%) [15, 248] and Hungary (58 \%) [249]. For unknown reasons, $R$. slovaca is found with lower prevalence or not detected at all in this species and occurs more often in D. marginatus $[245,250]$. 


\section{Francisella tularensis and Coxiella burnetii}

Tularaemia is a zoonosis caused by Francisella tularensis, a highly infectious Gram-negative coccobacillus which has been isolated from over 250 species of mammals, birds, reptiles, amphibians, fish and invertebrates. Francisella tularensis can be transmitted by several routes, including direct contact with infected body fluids, ingestion of contaminated food or water, inhalation of aerosols and arthropod bites [251]. Ticks have been shown to be infected with $F$. tularensis and F. tularensis-like microorganisms and even transstadial transmission has been demonstrated. Dermacentor reticulatus has been implicated in the transmission of $F$. tularensis in outbreaks in Russia [252]. However, and most importantly, the incrimination of this vector in transmitting the pathogen to humans has never been proved, and only circumstantial evidence for its vector competence exists [253, 254]. A recent study found no evidence of $F$. tularensis transovarial transmission in D. reticulatus [255].

A similar situation holds true for $Q$ fever, which is caused by Coxiella burnetii. It can infect a broad spectrum of hosts including livestock, pets, wildlife, birds, fish, reptiles and even invertebrates such as D. reticulatus [256, 257], and has several transmission routes. Although other ticks than $D$. reticulatus may readily transmit C. burnetii and F. tularensis in experimental systems, reports with irrefutable evidence of tick-transmitted Q fever in humans are scarce, if not non-existent [258]. Similarly to the case of $F$. tularensis obscured by F. tularensis-like endosymbionts, Coxiella-like bacteria are also widespread in ticks and may have been misidentified as $C$. burnetii as emphasised by Duron et al. [258]. Although ticks other than $D$. reticulatus may readily transmit $C$. burnetii in experimental systems, they only occasionally transmit the pathogen in the field. Indirectly, however, $D$. reticulatus may act as entrance for highly infectious agents, such as $F$. tularensis and $C$. burnetii, since bites of this species cause lesions in the host skin [38]. Thus, although transmission of $F$. tularensis and $C$. burnetii by D. reticulatus cannot be excluded, other transmission routes to humans play a more important role.

\section{Conclusions and future challenges}

A growing number of reports show that D. reticulatus is establishing new foci. We have reviewed the adaptive traits of this species to explain this successful invasion of new areas in the section "Life-cycle and ecology". The most important biological characters (intrinsic factors) of this species that contribute to the geographical spread are summarised in Fig. 11. Certainly, many driving forces influence the adaptability of a tick species to new areas as reviewed for $I$. ricinus recently [114]. The key extrinsic factors that have enabled the recent spread of $D$. reticulatus were reviewed in the section "Geographical distribution and recent spread" and are summarised in Fig. 12.

Many basic ecological traits of $D$. reticulatus still remain elusive and have to be explored in order to better understand the eco-epidemiological role of this vector species. We do not entirely understand why its larvae are hardly ever found by flagging, while they obviously find their (usual) vole host. Field data to show whether they are mainly inside the rodent nests (endophilous nidicoles) or only near but not within the nests (harbourage nidicoles) [7, 28] do not exist. Dermacentor reticulatus larvae in fact cannot be nidicolous by definition, since they can only hatch at places in the leaf litter where the engorged females are randomly dropped off from their hosts and lay eggs, except if gravid females are somehow able to lay eggs in the rodent burrows,

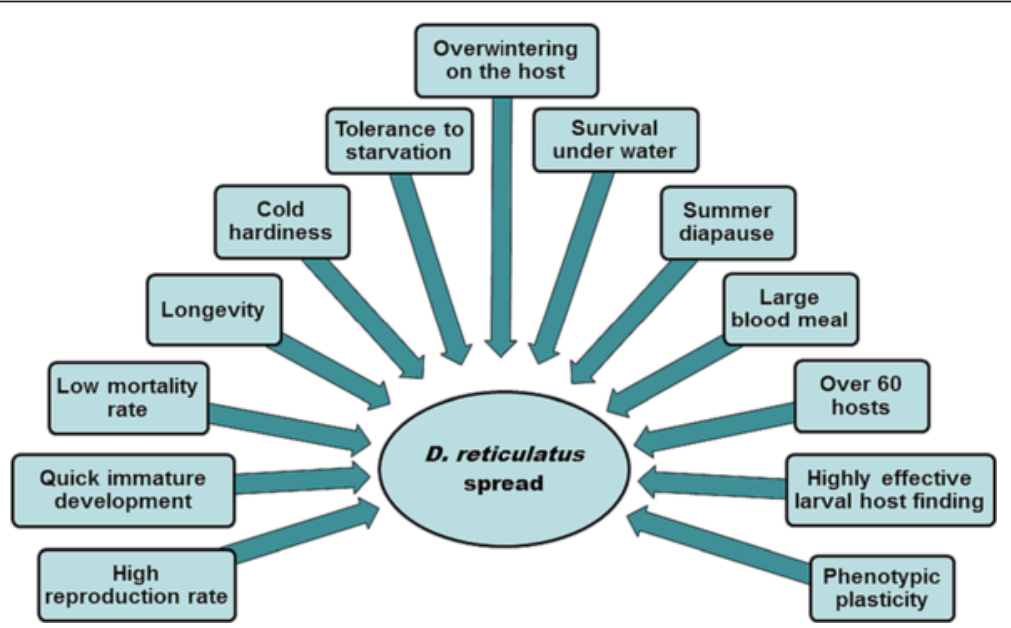

Fig. 11 Biological features (intrinsic factors) contributing to successful geographical spread of Dermacentor reticulatus (see details and references in the text) 


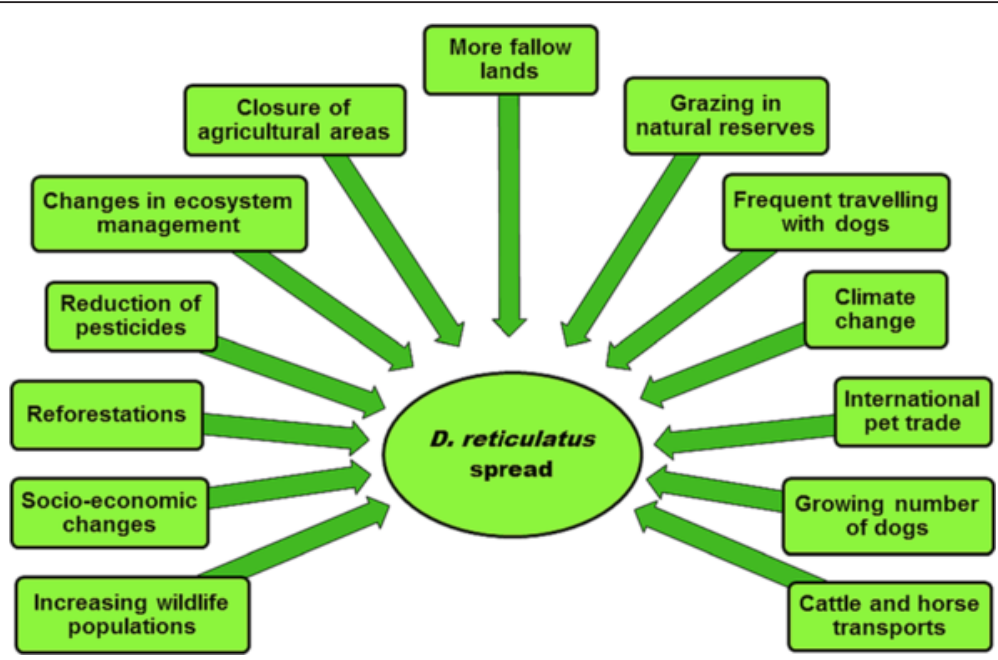

Fig. 12 Extrinsic factors contributing to successful geographical spread of Dermacentor reticulatus (see details and references in text)

which is highly unlikely as also pointed out by Pfäffle et al. [20]. Several alternative and mutually non-exclusive hypotheses can be proposed to explain the host-finding success of larvae despite their lack during sampling via flagging. First, there might be differences in the questing behaviour of $D$. reticulatus larvae compared to $I$. ricinus. Indeed, $D$. reticulatus larvae are able to move faster and they hardly if ever quest on vegetation compared to $I$. ricinus larvae (Hans Dautel, personal communication). Given their relatively high speed and dominantly horizontal movement, they have been shown to occupy a relatively large territory, several square meters [259]. Second, differences in the ecology and behaviour of the dominant host species (voles for $D$. reticulatus and mice for $I$. ricinus) may also account for this observation. A marked ecological difference is that voles build burrows with corridors some centimetres under the surface that often rise into the leaf litter. The nests are $50 \mathrm{~cm}$ under the surface in tree trunks, under dead wood or in the ground vegetation [260] and this might further increase the contact rate with larvae preferring leaf litter [20]. In contrast, yellow-necked field mice (A. flavicollis) tend to show arboreal occurrence by climbing on trees and nesting in bird nest boxes and tree hollows [261]. As a behavioural difference, yellow-necked field mice move differently through their habitat than bank voles ( $M y$. glareolus). Short distances are covered by running, while distances longer than two or three metres are covered by jumping, with a jump length up to $80 \mathrm{~cm}$ [262]. This can also lead to a dominance of $I$. ricinus (questing higher) and not $D$. reticulatus on mice. A third important factor is that the species structure in small rodent communities in central European floodplain forests is not uniform but changes along the moisture gradient. Bank voles dominate in the lower alluvial plains that hold water for a long time whereas in drier places, mice and voles show the same abundance [263]. Unlike mice, bank voles are capable of acquiring effective resistance against feeding larvae of Ixodes spp., resulting in reduced engorged weight and reduced survival of the nymphal stage [264-266]. Finally, field and laboratory experiments may also elucidate a possible host odour preference of larval $D$. reticulatus.

A deeper insight into host associations and their consequences on the eco-epidemiology of pathogens will undoubtedly benefit preventive approaches. The high preference of $D$. reticulatus for dogs together with the appearance of the tick in new areas will surely affect the emergence of certain pathogens too. As in the case of Dermacentor andersoni and Dermacentor variabilis, the abundant stray dogs and other free ranging dogs largely contributed to the high prevalence of Rickettsia rickettsii in ticks and led to hyperendemic foci of Rocky Mountain spotted fever in Mexico and south-west USA [7]. Similarly, the increase of dog populations might easily elevate the risk of infection by some pathogens transmitted by $D$. reticulatus, especially those that are maintained through transovarial transmission by the tick itself [267]. A similar effect exerted by horses was described in the case of TIBOLA infections and contact with horses [65].

Better understanding and mapping of the spread of $D$. reticulatus is pivotal to assess the (local) risk of infections transmitted by this vector species. A joint initiative of the European Food Safety Authority (EFSA) and the European Centre for Disease Prevention and Control (ECDC) resulted in a European network for sharing data on the geographic distribution of arthropod vectors transmitting human and animal disease agents (VectorNet), including D. reticulatus. A large database on the presence and 
distribution of vectors and pathogens in vectors in Europe and the Mediterranean basin is maintained, through a multidisciplinary network of experts and organizations, which (locally) collects these data. An up-to-date map on D. reticulatus (Fig. 9) can be found on the ECDC website [268]. Recent maps of this tick's distribution were published for Poland [17], Germany [127] and Europe [93] (Fig. 10), the digital dataset presented in the latter study are provided on the website http://epidemic-modeling.vetmeduni.ac.at/tickmodel.htm. Enhanced tick surveillance with harmonised approaches for comparison of data enabling follow-up of trends will improve the messages to policy makers, other stakeholders and to the general public on risks related to tick-borne diseases [114].

As reviewed in the veterinary and public health sections, there are a multitude of pathogens that can be transmitted or at least carried by D. reticulatus. However, we would like to emphasise that from the pathogen's point of view, since co-feeding larvae and nymphs are rare, there is a strong selection for pathogens that are transmitted transovarially or that persist in reservoir hosts. For those pathogens that are not transmitted transovarially or cause transient infections in hosts suitable for $D$. reticulatus, this tick species does not play an important role as a vector. As a future research topic, we would like to call attention to the importance of controlled laboratory and field experiments and studies exploring pathogen life-cycles. Molecular biology methods have evolved in an unprecedented way and many laboratories have sophisticated and ever cheaper tools as real-time PCR, microarrays and whole-genome sequencing become available, but fundamental studies clarifying reservoir and vector roles played in pathogen cycles lag behind.

Dermacentor reticulatus causes considerable public and veterinary health costs (surveillance, diagnosis and treatment) due to the pathogenic agents transmitted (Table 2). In addition, it can cause losses in livestock production. It has been quantified that the blood amount taken by 100 female $D$. reticulatus causes a loss of at least $400 \mathrm{ml}$ of blood from the host [23]. In heavily infested Belorussian cattle, the average milk yield decreased 2-3 litres per cow [269]. Animal health pharmaceutical companies spend hundreds of millions of Euros on research and development of new products and one of the leading areas is tick control on dogs, very often targeting D. reticulatus [270-277]. Dog owners also spend large amounts of money on preventing tick infestations. In the UK alone, the sale figures for ectoparasiticides have doubled in the last decade, exceeding 120 million Euros in 2014 [278]. Despite these financial efforts and the considerable and intensifying research, it seems that due to its adaptive traits, the tick is extending its range and increasing its epidemiologic impact. Dermacentor reticulatus is still on the rise.

\section{Additional files}

Additional file 1: Video 1. Male Dermacentor reticulatus showing vertical questing behaviour in the laboratory. Field-collected individuals were used on a $30 \mathrm{~cm}$ stick. (MP4 $3970 \mathrm{~kb}$ )

Additional file 2: Video 2. Male and female Dermacentor reticulatus individuals showing vertical questing behaviour in the laboratory. Field collected individuals were used on a 30 cm stick. (MP4 3679 kb)

\section{Acknowledgements \\ We are grateful for inspiring conversations on the topic with Agustín Estrada-Peña, Hans Dautel, Olaf Kahl, Alberto Guglielmone, Jeremy Gray, Michiel Wijnveld, Dmitry Apanaskevich and Márton Péti. We thank Alan R. Walker for providing his original drawings and Marieta Braks for the critical reading of the manuscript. The two anonymous reviewers provided great help in improving the manuscript. We are indebted to Jeremy Gray for his useful comments and language editing.}

\section{Funding}

This work was done under the frame of COST action TD1303 EurNegVec. PŠ was supported by the project "CEITEC - Central European Institute of Technology" (CZ.1.05/1.1.00/02.0068) from the European Regional Development Fund. G. F. was supported by the János Bolyai Research Scholarship of the Hungarian Academy of Sciences and an NKB and Research Faculty grants from the Faculty of Veterinary Science, Szent István University.

\section{Availability of data and material}

Not applicable.

\section{Authors' contributions}

GF and HS conceived the review. GF wrote the abstract and the sections 'Introduction', 'Systematics', 'Life-cycle and ecology', 'Veterinary health importance', 'Conclusions and future challenges', and contributed photos and figures. PŠ wrote the section 'Geographical distribution and recent spread' and contributed photos. SSz contributed with tables, figures, photos and videos. GM contributed with drawings and figures. HS wrote the section 'Public health importance'. All authors read, amended and approved the final manuscript.

Competing interests

The authors declare that they have no competing interests.

Consent for publication

Not applicable.

Ethics statement

Not applicable.

\section{Author details}

'Department of Parasitology and Zoology, Faculty of Veterinary Science, Szent István University, Budapest, Hungary. ²Department of Biology and Wildlife Diseases, Faculty of Veterinary Hygiene and Ecology, University of Veterinary and Pharmaceutical Sciences Brno, Brno, Czech Republic ${ }^{3}$ CEITEC-Central European Institute of Technology, University of Veterinary and Pharmaceutical Sciences Brno, Brno, Czech Republic. ${ }^{4}$ National Institute of Public Health and the Environment, Bilthoven, The Netherlands.

Received: 20 November 2015 Accepted: 18 May 2016

Published online: 01 June 2016

References

1. Šimo L, Kocáková P, Sláviková M. Dermacentor reticulatus (Acari, Ixodidae) female feeding in laboratory. Biol Bratislava. 2004;59:655-60.

2. Honzakova E. Analysis of some ecological factors influencing the development and survival of several tick species, PhD Thesis. Institute of Parasitology: Czech. Academy of Sciences; 1970.

3. Olsuf'ev NG. On ecology of the meadow tick Dermacentor pictus Herm., origin of its foci, and ways of eradicating it in the middle of the European part of 
RSFSR. Vopr krayevoy, Obs Eksp Parazitol i meditsinskoy Zool (Problems Reg Gen Exp Parasitol Med Zool Moscow. 1953;8:49-98. (In Russian).

4. Zahler M. Zur Ökologie von Dermacentor reticulatus (Fabricius, 1794) (Parasitiformes: Ixidida: Ixodidae). München: Diss. Med. Vet; 1994.

5. Tharme AP. Ecological studies on the tick Dermacentor reticulatus. PhD Thesis, University of Whales; 1993.

6. Randolph SE, Miklisová D, Lysy J, Rogers DJ, Labuda M. Incidence from coincidence: patterns of tick infestations on rodents facilitate transmission of tick-borne encephalitis virus. Parasitology. 1999;118:177-86.

7. Sonenshine D, Roe R, editors. Biology of ticks. Oxford, UK: Oxford University Press; 2014.

8. Guglielmone A, Robbins RG, Apanaskevich D, Petney TN, Estrada-Peña A, Horak IG. The hard ticks of the world. Dordrecht: Springer Science+Business Media; 2014.

9. Guglielmone A, Nava S. Names for Ixodidae (Acari: Ixodoidea): Valid, synonyms, incertae sedis, nomina dubia, nomina nuda, lapsus, incorrect and suppressed names - with notes on confusions and misidentifications. Zootaxa. 2014;3767: $1-256$

10. Arthur DR. Ticks: a monograph of the Ixodoidea part V. Cambridge, UK: Cambridge University Press; 1960.

11. Koch C. Systematische Übersicht über die Ordnung der Zecken. Arch für Naturgeschichte. 1844;10:217-39.

12. Hillyard P. Ticks of North-West Europe. Shrewsbury: Field Studies Council; 1996.

13. Estrada- Peña A, Bouattour A, Camicas J, Walker A. Ticks of domestic animals in the mediterranean region. Zaragoza: Universidad de Zaragoza; 2004.

14. Nowak M. Discovery of Dermacentor reticulatus (Acari: Amblyommidae) populations in the Lubuskie Province (Western Poland). Exp Appl Acarol Springer Netherlands. 2011;54:191-7.

15. Mierzejewska EJ, Pawełczyk A, Radkowski M, Welc-Falęciak R, Bajer A. Pathogens vectored by the tick, Dermacentor reticulatus, in endemic regions and zones of expansion in Poland. Parasit Vectors. 2015;8:490.

16. Jaenson TGT, Talleklint L, Lundqvist $L$, Olsen B, Chirico J, Mejlon $H$. Geographical distribution, host associations, and vector roles of ticks (Acari: Ixodidae, Argasidae) in Sweden. J Med Entomol. 1994;31:240-56

17. Mierzejewska EJ, Estrada-Peña A, Alsarraf M, Kowalec M, Bajer A. Mapping of Dermacentor reticulatus expansion in Poland in 2012-2014. Ticks Tick Borne Dis. 2016;7:94-106

18. Zahler M, Gothe R. Evidence for the reproductive isolation of Dermacentor marginatus and Dermacentor reticulatus (Acari: Ixodidae) ticks based on cross-breeding, morphology and molecular studies. Exp Appl Acarol. 1997; 21:685-96.

19. Immler R. Untersuchungen zur Biologie und Ökologie der Zecke Dermacentor reticulatus (Fabricius, 1794) (Ixodidae) in einem endemischen Vorkommensgebiet. Ph.D. thesis. University of Basel; 1973.

20. Pfäffle M, Littwin N, Petney T. Host preferences of immature Dermacentor reticulatus (Acari: Ixodidae) in a forest habitat in Germany. Ticks Tick Borne Dis. 2015;6:508-15.

21. Paziewska A, Zwolińska L, Harris PD, Bajer A, Siński E. Utilisation of rodent species by larvae and nymphs of hard ticks (Ixodidae) in two habitats in NE Poland. Exp Appl Acarol. 2010;50:79-91.

22. Nosek J. The ecology and public health importance of Dermacentor marginatus and D. reticulatus ticks in Central Europe. Folia Parasitol (Praha). 1972;19:93-102

23. Balashov YS. Bloodsucking ticks (Ixodoidea) - vectors of diseases of man and animals. In: Miscellaneous Publications of the Entomological Society of America. Leningrad: Nauka Publishers; 1968.

24. Slovak M, Labuda M, Marley SE. Mass laboratory rearing of Dermacentor reticulatus ticks (Acarina, Ixodidae). Biol Bratislava. 2002;57:261-6.

25. Földvári G, Farkas R. Ixodid tick species attaching to dogs in Hungary. Vet Parasitol. 2005;129:125-31.

26. Földvári G, Márialigeti M, Solymosi N, Lukács Z, Majoros G, Kósa JP, et al. Hard ticks infesting dogs in Hungary and their infection with Babesia and Borrelia species. Parasitol Res. 2007;101:25-34.

27. Duscher GG, Feiler A, Leschnik M, Joachim A. Seasonal and spatial distribution of ixodid tick species feeding on naturally infested dogs from Eastern Austria and the influence of acaricides/repellents on these parameters. Parasit Vectors. 2013;6:76.

28. Sonenshine D. Biology of ticks, vol. 2. New York: Oxford University Press: 1993.

29. Tokhov YM, Lutsuk SN, Dyachenko W. Phenology of ixodid ticks of the genus Dermacentor in the Central Ciscaucasia. Entomol Rev. 2014;94:426-33.
30. Sonenshine DE. Biology of Ticks, vol. 1. Oxford, UK: Oxford University Press; 1991.

31. Gilot B, Pautou G, Immler R, Moncada E. Suburban biotopes of Dermacentor reticulatus (Fabricius, 1794) (Ixodoidea). Preliminary study. Rev Suisse f Zool. 1973;80:411-30

32. Široký P, Kubelová M, Bednář M, Modrý D, Hubálek Z, Tkadlec E. The distribution and spreading pattern of Dermacentor reticulatus over its threshold area in the Czech Republic-How much is range of this vector expanding? Vet Parasitol. 2011;183:130-5.

33. Szymanski S. Seasonal activity of Dermacentor reticulatus (Fabricuis, 1794) (Acarina, Ixodidae) in Poland. I: Adults. Acta Parasitol Pol. 1987b;31: 247-55.

34. Hornok S, Farkas R. Influence of biotope on the distribution and peak activity of questing ixodid ticks in Hungary. Med Vet Entomol. 2009;23:41-6.

35. Kubelová M. Canine babesiosis at the door! spreading into the Czech Republic, PhD Thesis. Brno: University of Veterinary and Pharmaceutical Sciences; 2015.

36. Kiszewski AE, Matuschka FR, Spielman A. Mating strategies and spermiogenesis in ixodid ticks. Annu Rev Entomol United States. 2001;46:167-82.

37. Meyer-König A, Zahler M, Gothe R. Studies on the critical water mass and the rehydration potential of unfed adult Dermacentor marginatus and $D$. reticulatus ticks (Acari: Ixodidae). Exp Appl Acarol. 2001;25:505-16.

38. Buczek A, Bartosik K, Zając Z, Stanko M. Host-feeding behaviour of Dermacentor reticulatus and Dermacentor marginatus in mono-specific and inter-specific infestations. Parasit Vectors. 2015;8:470.

39. Sieberz J, Gothe R. Modus operandi of oviposition in Dermacentor reticulatus (Acari: Ixodidae). Exp Appl Acarol. 2000;24:63-76.

40. Kasyanov A. Winter parasitism by ticks of the Family Ixodidae on farm animals in Khabarovsk Region. Veterinarya. 1947;24:14-5. (In Russian)

41. Schöl H, Sieberz J, Göbel E, Gothe R. Morphology and structural organization of Gene's organ in Dermacentor reticulatus (Acari: Ixodidae) Exp Appl Acarol. 2001;25:327-52.

42. Nosek J. Overwintering cycles of Dermacentor ticks. Angew Parasitol. 1979; 20:34-7.

43. Földvári G, Farkas R. Review of literature relating to Dermacentor reticulatus (Acari: Ixodidae) and newer data on the occurrence in Hungary. Magy Allatorvosok Lapja. 2005;127:289-98. (In Hungarian with English abstract).

44. Razumova I. The activity of Dermacentor reticulatus Fabr. (Ixodidae) ticks in nature. Med Parazitol (Mosk). 1998:4:8-14. (In Russian).

45. Martinod S, Gilot B. Epidemiology of canine babesiosis in relation to the activity of Dermacentor reticulatus in southern Jura (France). Exp Appl Acarol. 1991;11:215-22.

46. Belozerov VN. Diapause and quiescence as two main kinds of dormancy and their significance in life cycles of mites and ticks (Chelicerata: Arachnida: Acari). Part 2. Parasitiformes. Acarina. 2009;17:3-32.

47. Belozerov V. Diapause and biological rhythms in ticks. In: F. D. Obenchain and R. Galun, editors. Physiol. Ticks. Oxford: Pergamon Press; 1982. p. 469500.

48. Estrada-Peña A, Gray JS, Kahl O, Lane RS, Nijhof AM. Research on the ecology of ticks and tick-borne pathogens-methodological principles and caveats. Front Cell Infect Microbiol. 2013;3:29.

49. Bajer A, Welc-Falęciak R, Bednarska M, Alsarraf M, Behnke-Borowczyk J, Siński E, et al. Long-term spatiotemporal stability and dynamic changes in the haemoparasite community of bank voles (Myodes glareolus) in NE Poland. Microb Ecol. 2014;68:196-211.

50. Akimov I, Nebogatkin I. Distribution of ticks of the genus Dermacentor (Acari, Ixodidae) in Ukraine. Vestn Zool. 2011;45:35-40.

51. Fedorov $V$. Ticks of the superfamily Ixodoidea of birds and their nests in western Siberia]. In: Cherepanov A, Mater L, editors. Transcontinental Connect. Migr. birds their role Distrib. arboviruses. 1972. p. 384-8 (In Russian, NAMRU - 3 translation 1494).

52. Hornok S, de la Fuente J, Horváth G, de Mera IG F, Wijnveld M, Tánczos B, et al. Molecular evidence of Ehrlichia canis and Rickettsia massiliae in ixodid ticks of carnivores from South Hungary. Acta Vet Hung. 2013;61:42-50.

53. Thompson GB, Arthur DR. VI.--Records of ticks collected from birds in the British Isles.-2. J Nat Hist Ser 12. 1955;8:57-60.

54. Kislenko GS, Korotkov IS, Shmakov LV. The meadow tick Dermacentor reticulatus in natural foci of tick-borne encephalitis in Udmurtia. Parazitologiia USSR. 1987;21:730-5. (In Russian).

55. Gilot B, Marjolet M. Contribution a l'etude du parasitisme humain par les tiques (Ixodidae et Argasidae) plus particulierement dans le sud-est de la France. Med Mal Infect. 1982;12:340-51. 
56. Fedorov V. Ixodoidea ticks on humans in western Siberia. Med Parazit Moskva. 1968;97:615-6. (In Russian), NAMRU - 3 translation 390.

57. Fedorov V. On the blood-sucking mites on amphibians and reptiles in the Western Siberia. Tezisy Dokl Vtorogo Akarol Soveshchaniya, Kiev. 1970;2: 185-6. (In Russian), NAMRU - 3 translation 1493.

58. Lác J, Cyprich D, Kiefer M. Zeckenartige (Ixodidae) als Parasiten von Eidechsen unter den ökologischen Bedingungen der Slowakei. Zool List. 1972;21:133-44

59. Neumann LG. Acarina. Ixodidea. Das Tierreich. R. Friedlander und Sohn; 1911.

60. Mierzejewska EJ, Welc-Faleciak R, Karbowiak G, Kowalec M, Behnke JM, Bajer A. Dominance of Dermacentor reticulatus over Ixodes ricinus (Ixodidae) on livestock, companion animals and wild ruminants in eastern and central Poland. Exp Appl Acarol. 2015;66:83-101.

61. Chitimia-Dobler L. Spatial distribution of Dermacentor reticulatus in Romania. Vet Parasitol. 2015;214:219-23.

62. Dautel H, Dippel C, Oehme R, Hartelt K, Schettler E. Evidence for an increased geographical distribution of Dermacentor reticulatus in Germany and detection of Rickettsia sp. RpA4. Int J Med Microbiol. 2006;296:149-56.

63. Estrada-Peña A, Jongejan F. Ticks feeding on humans : a review of records on human-biting Ixodoidea with special reference to pathogen transmission. Exp Appl Acarol. 1999;23:685-715.

64. Földvári G, Rigó K, Lakos A. Transmission of Rickettsia slovaca and Rickettsia raoultii by male Dermacentor marginatus and Dermacentor reticulatus ticks to humans. Diagn Microbiol Infect Dis. 2013;76:387-9.

65. Lakos A, Körösi A, Földvári G. Contact with horses is a risk factor for tickborne lymphadenopathy (TIBOLA): a case control study. Wien Klin Wochenschr. 2012;124:611-7.

66. Rieg S, Schmoldt S, Theilacker C, de With K, Wölfel S, Kern W, et al. Tickborne lymphadenopathy (TIBOLA) acquired in Southwestern Germany. BMC Infect Dis. 2011;11:167.

67. Cerny V, Szymanski S, Dusbabek F, Daniel M, Honzakova E. Survival of unfed Dermacentor reticulatus (Fabr.) adults under natural conditions. Wiad Parazytol. 1982;28:27-31.

68. Szymanski S. Distribution of the tick Dermacentor reticulatus (Fabricus, 1794)(Ixodidae) in Poland. Acta Parasitol Pol. 1986;31:143-54.

69. Jongejan F, Ringenier M, Putting M, Berger L, Burgers S, Kortekaas R, et al. Novel foci of Dermacentor reticulatus ticks infected with Babesia canis and Babesia caballi in the Netherlands and in Belgium. Parasit Vectors. 2015:8:1-10.

70. Gilot B, Robin Y, Pautou G, Moncada E, Vigny F. Ecology and pathogenic role of Dermacentor reticulatus (Fabricius, 1794) (Ixodoidea) in south-eastern France. Acarologia. 1974;16:220-49.

71. Pomerantsev B. [lxodid ticks (Ixodidae), Fauna SSSR]. Paukoobraznye. Moskva, Leningrad: Izdatelstvo Akademii Nauk SSSR; 1950. (In Russian).

72. Olsuf'ev NG. On the origin of the foci of the tick Dermacentor pictus Herm. in the southern part of the province of Moskow. Leningrad: 2nd Conf. Parasitol. Probl; 1940. p. 26-8. (In Russian).

73. Petney TN, Pfäffle MP, Skuballa JD. An annotated checklist of the ticks (Acari: Ixodida) of Germany. Syst Appl Acarol. 2012;17:115-70.

74. Hoogstraal $\mathrm{H}$. Ticks in relation to human diseases caused by Rickettsia species. Annu Rev Entomol. 1967;12:377-420.

75. Földvári G. Studies of ticks (Acari: Ixodidae) and tick-borne pathogens of dogs in Hungary, PhD Thesis. Budapest: Faculty of Veterinary Science, Szent István University; 2005.

76. Hubalek Z, Halouzka J, Juricova Z. Host-seeking activity of ixodid ticks in relation to weather variables. J Vector Ecol. 2003;28:159-65.

77. Zygner W, Górski P, Wedrychowicz H. New localities of Dermacentor reticulatus tick (vector of Babesia canis canis) in central and eastern Poland. Pol J Vet Sci. 2009;12:549-55.

78. Siuda K, Sebesta R. Effect of temperature and relative humidity on the development and hatching of larvae of the tick Dermacentor reticulatus (Fabricius, 1794) (Acari: Ixodida). Wiad Parazytol. 1999;45:553-4.

79. Hornok S, Meli ML, Gönczi E, Halász E, Takács N, Farkas R, et al. Occurrence of ticks and prevalence of Anaplasma phagocytophilum and Borrelia burgdorferi s.l. in three types of urban biotopes: Forests, parks and cemeteries. Ticks Tick Borne Dis. 2014;5:785-9.

80. Biernat B, Karbowiak G, Werszko J, Stańczak J. Prevalence of tick-borne encephalitis virus (TBEV) RNA in Dermacentor reticulatus ticks from natural and urban environment, Poland. Exp Appl Acarol. 2014;64:543-51.

81. Heile C, Heydorn A-O, Scheln E. Dermacentor reticulatus (Fabricius, 1794) Verbreitung, Biologie und Vektor von Babesia canis in Deutschland. Berl Munch Tierarztl Wochenschr. 2006;119(6):330-4.
82. Karbowiak G. The occurrence of the Dermacentor reticulatus tick - its expansion to new areas and possible causes. Ann Parasitol. 2014;60:37-47.

83. Bullová E, Lukán M, Stanko M, Petko B. Spatial distribution of Dermacentor reticulatus tick in Slovakia in the beginning of the 21st century. Vet Parasitol. 2009;165:357-60.

84. Biaduń W. New habitats of Dermacentor reticulatus (Fabricius, 1794) in the Lublin region. Polish J Env Stud. 2011;20:263-6.

85. Hamel D, Silaghi C, Zapadynska S, Kudrin A, Pfister K. Vector-borne pathogens in ticks and EDTA-blood samples collected from client-owned dogs, Kiev, Ukraine. Ticks Tick Borne Dis. 2013;4:152-5.

86. Uspensky I. Tick pests and vectors (Acari: Ixodoidea) in European towns: Introduction, persistence and management. Ticks Tick Borne Dis. 2014;5:41-7.

87. Rizzoli A, Silaghi C, Obiegala A, Rudolf I, Hubalek Z, Földvári G, et al. Ixodes ricinus and its transmitted pathogens in urban and peri-urban areas in Europe: new hazards and relevance for public health. Front Public Heal. 2014;2:251.

88. Földvári G, Rigó K, Jablonszky M, Biró N, Majoros G, Molnár V, et al. Ticks and the city: ectoparasites of the Northern white-breasted hedgehog (Erinaceus roumanicus) in an urban park. Ticks Tick Borne Dis. 2011;2:231-4.

89. Schille F. Entomologie aus der Mammut- und Rhinoceroszeit Galiziens. Entomol Zeitschrift. 1916;30:42-3.

90. Feider Z. Acaromorpha. Suprafamilia Ixodoidea. Arachnida. Fauna Republicii Populare Romane: Vol.5., Fasc.2. Bucharest: Editura Academiei Republicii Populare Romane; 1965.

91. Kolonin G. World distribution of Ixodid ticks. Genera Dermacentor, Anocentor Cosmiomma, Dermacentonomma, Nosomma, Rhipicentor, Rhipicephalus, Boophilus, Margaropus, Anomalohimalaya. Moscow: Nauka; 1984.

92. Kolonin G. Fauna of ixodid ticks of the world (Acari, Ixodidae). Moscow; 2009 http://www.kolonin.org.

93. Rubel F, Brugger K, Pfeffer M, Chitimia-Dobler L, Didyk YM, Leverenz S, et al. Geographical distribution of Dermacentor marginatus and Dermacentor reticulatus in Europe. Ticks Tick Borne Dis. 2016;7:224-33.

94. Randolph SE, EDEN-TBD sub-project team. Human activities predominate in determining changing incidence of tick-borne encephalitis in Europe. Eurosurveillance. 2010;15:24-31.

95. Csányi S, Tóth K, Schally G. Hungarian Game Management Database 19602013. Gödöllő; 2013. http://ova.info.hu/vg_stat/VA-1960-1994-2013.pdf.

96. Federation, European Pet Food Industry [Internet]. 2012 [cited 2015 Nov 10]. Available from: www.fediaf.org

97. Occupy for Animals! [Internet]. 2015 [cited 2015 Nov 10]. Available from: http://www.occupyforanimals.net/europes-homeless-animals.html

98. Korenberg El, Kovalevskii YV. Main features of tick-borne encephalitis ecoepidemiology in Russia. Zentralbl Bakteriol. 1999;289:525-39.

99. Piesman J, Eisen L. Prevention of tick-borne diseases. Annu Rev Entomol. 2008;53:323-43.

100. Santos-Silva M, Sousa R, Santos AS, Lopes D, Queijo E, Doreta A, et al. Ticks and tick-borne Rickettsiae surveillance in Montesinho Natural Park, Portugal. Ann N Y Acad Sci. 2006;1078:137-42.

101. Barandika JF, Berriatua E, Barral M, Juste RA, Anda P, Garcia-Perez AL. Risk factors associated with ixodid tick species distributions in the Basque region in Spain. Med Vet Entomol. 2006;20:177-88.

102. Dominguez G. North Spain (Burgos) wild mammals ectoparasites. Parasite. 2004;11:267-72.

103. Estrada-Peña A, Farkas R, Jaenson TGT, Koenen F, Madder M, Pascucci I, et al. Association of environmental traits with the geographic ranges of ticks (Acari: Ixodidae) of medical and veterinary importance in the western Palearctic. A digital data set. Exp Appl Acarol. 2013;59:351-66.

104. Bonnet S, de la Fuente J, Nicollet P, Liu X, Madani N, Blanchard B, et al. Prevalence of tick-borne pathogens in adult Dermacentor spp. ticks from nine collection sites in France. Vector Borne Zoonotic Dis. 2013;13:226-36

105. Michelet $L$, Bonnet S, Madani N, Moutailler S. Discriminating Francisella tularensis and Francisella-like endosymbionts in Dermacentor reticulatus ticks: Evaluation of current molecular techniques. Vet Microbiol. 2013;163:399-403.

106. René-Martellet M, Moro CV, Chêne J, Bourdoiseau G, Chabanne L, Mavingui P. Update on epidemiology of canine babesiosis in Southern France. BMC Vet Res. 2015;11:223.

107. Nijhof AM, Bodaan C, Postigo M, Nieuwenhuijs H, Opsteegh M, Franssen L, et al. Ticks and associated pathogens collected from domestic animals in the Netherlands. Vector Borne Zoonotic Dis. 2007;7:585-95.

108. Cochez C, Lempereur L, Madder M, Claerebout E, Simons L, De Wilde N, et al. Foci report on indigenous Dermacentor reticulatus populations in 
Belgium and a preliminary study of associated babesiosis pathogens. Med Vet Entomol. 2012;26:355-8.

109. Obsomer V, Wirtgen M, Linden A, Claerebout E, Heyman P, Heylen D, et al. Spatial disaggregation of tick occurrence and ecology at a local scale as a preliminary step for spatial surveillance of tick-borne diseases: general framework and health implications in Belgium. Parasit Vectors. 2013;6:190.

110. Hofmeester TR, Van Der Lei P-B, Docters Van Leeuwen A, Sprong H, Van Wieren SE. New foci of Haemaphysalis punctata and Dermacentor reticulatus in the Netherlands. Ticks Tick Borne Dis. 2016;7:367-70.

111. Immler R, Aeschlimann A, Büttiker W, Diehl P, Eichenberger G, Weiss N. Über das Vorkommen von Dermacentor-Zecken (Ixodoidea) in der Schweiz. Bull Soc Entomol Suisse. 1970;43:99-110.

112. Schaarschmidt D, Gilli U, Gottstein B, Marreros N, Kuhnert P, Daeppen JA, et al. Questing Dermacentor reticulatus harbouring Babesia canis DNA associated with outbreaks of canine babesiosis in the Swiss Midlands. Ticks Tick Borne Dis. 2013;4:334-40.

113. Eichenberger RM, Deplazes P, Mathis A. Ticks on dogs and cats: a pet owner-based survey in a rural town in northeastern Switzerland. Ticks Tick Borne Dis. 2015:6:267-71.

114. Medlock JM, Hansford KM, Bormane A, Derdakova M, Estrada-Peña A, George J-C, et al. Driving forces for changes in geographical distribution of Ixodes ricinus ticks in Europe. Parasit Vectors. 2013;6:1.

115. Tijsse-Klasen E, Hansford KM, Jahfari S, Phipps P, Sprong H, Medlock JM. Spotted fever group rickettsiae in Dermacentor reticulatus and Haemaphysalis punctata ticks in the UK. Parasit Vectors. 2013;6:212.

116. Sréter T, Széll Z, Varga I. Spatial distribution of Dermacentor reticulatus and Ixodes ricinus in Hungary: evidence for change? Vet Parasitol. 2005;128:347-51.

117. Széll Z, Sréter-Lancz Z, Márialigeti K, Sréter T. Temporal distribution of Ixodes ricinus, Dermacentor reticulatus and Haemaphysalis concinna in Hungary. Vet Parasitol. 2006;141:377-9.

118. Hornok S, Horváth G. First report of adult Hyalomma marginatum rufipes (vector of Crimean-Congo haemorrhagic fever virus) on cattle under a continental climate in Hungary. Parasit Vectors. 2012;5:170.

119. Černý V. The tick fauna of Czechoslovakia. Folia Parasitol (Praha). 1972;19:87-92.

120. Kubelová M, Tkadlec E, Bednár M, Roubalová E, Siroký P. West-to-east differences of Babesia canis canis prevalence in Dermacentor reticulatus ticks in Slovakia. Vet Parasitol. 2011;180:191-6.

121. Majláthová V, Majláth I, Vichova B, Gul'ova I, Derdakova M, Sesztakova E, et al. Polymerase chain reaction confirmation of Babesia canis canis and Anaplasma phagocytophilum in dogs suspected of babesiosis in Slovakia. Vector Borne Zoonotic Dis. 2011;11:1447-51.

122. Sixl W. Zecken und Wurmeier bei Hunden und Katzen in der Steiermark (Arachnida; Nematoda). Mitteilungen Abt Zool Landesmus Joanneum. 1975:4:59-60.

123. Leschnik MW, Khanakah G, Duscher G, Wille-Piazzai W, Hörweg C, Joachim $A$, et al. Species, developmental stage and infection with microbial pathogens of engorged ticks removed from dogs and questing ticks. Med Vet Entomol. 2012;26:440-6.

124. Duscher GG, Kübber-Heiss A, Richter B, Suchentrunk F. A golden jackal (Canis aureus) from Austria bearing Hepatozoon canis-import due to immigration into a non-endemic area? Ticks Tick Borne Dis. 2013:4:133-7.

125. Rosický B. Important ticks of the genus Dermacentor in Czechoslovakia. Folia Zool Entomol Brno. 1952;1:85-9. (In Czech).

126. Pluta S, Hartelt K, Oehme R, Mackenstedt U, Kimmig P. Prevalence of Coxiella burnetii and Rickettsia spp. in ticks and rodents in southern Germany. Ticks Tick Borne Dis. 2010;1:145-7.

127. Rubel F, Brugger K, Monazahian M, Habedank B, Dautel H, Leverenz S, et al. The first German map of georeferenced ixodid tick locations. Parasit Vectors. 2014:7:477.

128. Kadulski S, Izdebska J. New data on distribution of Dermacentor reticulatus (Fabr.) (Acari, Ixodidae) in Poland. Arthropods. Invasions their Control. 2009. p. 53-8.

129. Stanczak J. Detection of spotted fever group (SFG) rickettsiae in Dermacentor reticulatus (Acari: Ixodidae) in Poland. Int J Med Microbiol. 2006;296:144-8.

130. Buczek A, Bartosik KA, Wisniowski L, Tomasiewicz K. Changes in population abundance of adult Dermacentor reticulatus (Acari: Amblyommidae) in longterm investigations in eastern Poland. Ann Agric Environ Med. 2013;20:269-72.

131. Mierzejewska EJ, Alsarraf M, Behnke JM, Bajer A. The effect of changes in agricultural practices on the density of Dermacentor reticulatus ticks. Vet Parasitol. 2015;211:259-65.
132. Ploj M. Occurrence of ticks (Acarina: Ixodidae) and their development in Prekmurje (Lendavsko Dolinsko). Diploma Thesis, Univ. Ljubljana; 2007.

133. Krčmar S, Vereš M, Trliar T. Fauna of hard ticks (Acari: Ixodidae) in different habitats in Croatian part of Baranja. Šumarski List. 2014;5-6:309-14.

134. Jemersic L, Dezdek D, Brnic D, Prpic J, Janicki Z, Keros T, et al. Detection and genetic characterization of tick-borne encephalitis virus (TBEV) derived from ticks removed from red foxes (Vulpes vulpes) and isolated from spleen samples of red deer (Cervus elaphus) in Croatia. Ticks Tick Borne Dis. 2014:5:7-13.

135. Mihaljica D, Radulović Z, Tomanović S, Cakić S, Penezić A, Milutinović M. Molecular detection of Babesia spp. in ticks in northern Serbia. Arch Biol Sci Belgrade. 2012;64:1591-8.

136. Tomanović $\mathrm{S}$, Chochlakis D, Radulović Z, Milutinović M, Cakić S, Mihaljica D, et al. Analysis of pathogen co-occurrence in host-seeking adult hard ticks from Serbia. Exp Appl Acarol. 2013;59:367-76.

137. Omeragic J. Ixodid ticks in Bosnia and Herzegovina. Exp Appl Acarol. 2011; 53:301-9.

138. Mihalca AD, Dumitrache MO, Magdas C, Gherman CM, Domsa C, Mircean $V$, et al. Synopsis of the hard ticks (Acari: Ixodidae) of Romania with update on host associations and geographical distribution. Exp Appl Acarol. 2012:58:183-206.

139. Coipan E, Vladimirescu AF, Ciolpan O, Teodorescu I. Tick species (Acari: Ixodoidea) distribution, seasonality and host associations in Romania. Trav du Muséum Natl d'Histoire Nat «Grigore Antipa». 2011;54:301-17.

140. Movila A, Deriabina T, Morozov A, Sitnicova N, Toderas I, Uspenskaia I, et al. Abundance of adult ticks (Acari: Ixodidae) in the Chernobyl nuclear power plant exclusion zone. J Parasitol. 2012;98:883-4.

141. Reye AL, Stegniy V, Mishaeva NP, Velhin S, Hübschen JM, Ignatyev G, et al. Prevalence of tick-borne pathogens in Ixodes ricinus and Dermacentor reticulatus ticks from different geographical locations in Belarus. PLoS One. 2013;8:14-6.

142. Paulauskas A, Radzijevskaja J, Mardosaite-Busaitiene D, Aleksandraviciene A, Galdikas M, Krikstolaitis R. New localities of Dermacentor reticulatus ticks in the Baltic countries. Ticks Tick Borne Dis. 2015;6:630-5.

143. Paulauskas A, Radzijevskaja J, Turčinavičiene J, Ambrasiene D, Galdikaite E. Data on some ixodid tick species (Acari, Ixodidae) in the Baltic countries. Naujos ir Retos Liet Vabzdžių Rūšys (New rare Lith Insect Species). 2010:22:43-51.

144. Karbowiak G, Vichová B, Slivinska K, Werszko J, Didyk J, Petko B, et al. The infection of questing Dermacentor reticulatus ticks with Babesia canis and Anaplasma phagocytophilum in the Chernobyl exclusion zone. Vet Parasitol. 2014:204:372-5.

145. Filippova N. Ixodid ticks of subfamily Amblyomminae. Fauna of Russia and neighbouring countries. St. Petersburg: Nauka; 1997. (in Russian).

146. Gökçe E, Kırmızıgül A, Taşcı G, Uzlu E, Gündüz N, Vatansever Z. The first time clinical and parasitological determination of Babesia canis canis in dogs in Turkey. Kafkas Univ Vet Fac J. 2013;19:717-20.

147. Rar V, Maksimova T, Zakharenko L, Bolykhina S, Dobrotvorsky A, Morozova O. Babesia DNA detection in canine blood and Dermacentor reticulatus ticks in Southwestern Siberia, Russia. Vector-Borne Zoonotic Dis. 2005;5:285-7.

148. Dedkov VG, Markelov ML, Gridneva KA, Bekova MV, Gmyl AP, Kozlovskaya LI, et al. Prevalence of Kemerovo virus in ixodid ticks from the Russian Federation. Ticks Tick Borne Dis. 2014:5:651-5.

149. Shchuchinova LD, Kozlova IV, Zlobin VI. Influence of altitude on tick-borne encephalitis infection risk in the natural foci of the Altai Republic, Southern Siberia. Ticks Tick Borne Dis. 2015;6:322-9.

150. Kurilshikov A, Livanova NN, Fomenko NV, Tupikin AE, Rar VA, Kabilov MR, et al. Comparative metagenomic profiling of symbiotic bacterial communities associated with Ixodes persulcatus, Ixodes pavlovskyi and Dermacentor reticulatus ticks. PLoS One. 2015;10:e0131413.

151. Livanova N, Livanov S, Panov V. Characteristics of the distribution of ticks Ixodes persulcatus and Ixodes pavlovskyi at the border between the forest and forest-steppe zones in the territory near Ob River. Parazitologiiaa. 2011; 45:94-103 (In Russian).

152. Chen Z, Yang X, Bu F, Yang X, Yang X, Liu J. Ticks (Acari: Ixodoidea: Argasidae, Ixodidae) of China. Exp Appl Acarol. 2010;51:393-404.

153. Mehlhorn H, Schein E. The piroplasms: life cycle and sexual stages. Adv Parasitol. 1984:23:37-103.

154. Uilenberg G. Babesia - A historical overview. Vet Parasitol. 2006;138:3-10.

155. Matijatko V, Torti M, Schetters TP. Canine babesiosis in Europe: how many diseases? Trends Parasitol. 2012;28:99-105. 
156. Carcy B, Randazzo S, Depoix D, Adaszek L, Cardoso L, Baneth G, et al. Classification of Babesia canis strains in Europe based on polymorphism of the Bc28.1-gene from the Babesia canis Bc28 multigene family. Vet Parasitol. 2015;211:111-23.

157. Bourdoiseau G. Canine babesiosis in France. Vet Parasitol. 2006;138:118-25.

158. Rar VA, Fomenko NV, Dobrotvorsky AK, Livanova NN, Rudakova SA, Fedorov EG, et al. Tickborne pathogen detection, Western Siberia, Russia. Emerg Infect Dis. 2005;11:1708-15.

159. Schreiber C, Krücken J, Beck S, Maaz D, Pachnicke S, Krieger K, et al. Pathogens in ticks collected from dogs in Berlin/Brandenburg, Germany. Parasit Vectors. 2014;7:535.

160. Zanet S, Trisciuoglio A, Bottero E, de Mera IGF, Gortazar C, Carpignano MG, et al. Piroplasmosis in wild life: Babesia and Theileria affecting free-ranging ungulates and carnivores in the Italian Alps. Parasit Vectors. 2014;7:70.

161. Farkas R, Takács N, Hornyák A, Nachum-Biala Y, Hornok S, Baneth G. First report on Babesia cf. microti infection of red foxes (Vulpes vulpes) from Hungary. Parasit Vectors. 2015:8:55.

162. Duscher GG, Fuehrer H-P, Kübber-Heiss A. Fox on the run - molecular surveillance of fox blood and tissue for the occurrence of tick-borne pathogens in Austria. Parasit Vectors. 2014;7:521.

163. Majláthová V, Hurníková Z, Majláth I, Petko B. Hepatozoon canis infection in Slovakia: imported or autochthonous? Vector Borne Zoonotic Dis. 2007;7:199-202

164. Cardoso L, Cortes HCE, Reis A, Rodrigues P, Simões M, Lopes AP, et al. Prevalence of Babesia microti-like infection in red foxes (Vulpes vulpes) from Portugal. Vet Parasitol. 2013;196:90-5.

165. Hodžić A, Alić A, Fuehrer H-P, Harl J, Wille-Piazzai W, Duscher GG. A molecular survey of vector-borne pathogens in red foxes (Vulpes vulpes) from Bosnia and Herzegovina. Parasit Vectors. 2015;8:88.

166. Farkas R, Solymosi N, Takács N, Hornyák Á, Hornok S, Nachum-Biala Y, et al. First molecular evidence of Hepatozoon canis infection in red foxes and golden jackals from Hungary. Parasit Vectors. 2014;7:303.

167. Erdélyi K, Mezősi L, Vladov S, Földvári G. Fatal acute babesiosis in captive grey wolves (Canis lupus) due to Babesia canis. Ticks Tick Borne Dis. 2014;5:281-3.

168. Martinod S, Laurent N, Moreau Y. Resistance and immunity of dogs against Babesia canis in an endemic area. Vet Parasitol. 1986;19:245-54.

169. Martinod S, Brossard M, Moreau Y. Immunity of dogs against Babesia canis, its vector tick Dermacentor reticulatus, and Ixodes ricinus in endemic area. J Parasitol. 1985;71:269-73.

170. Kubelová M, Sedlák K, Panev A, Široký P. Conflicting results of serological, PCR and microscopic methods clarify the various risk levels of canine babesiosis in Slovakia: a complex approach to Babesia canis diagnostics. Vet Parasitol. 2013;191:353-7.

171. Bajer A, Rodo A, Welc-Falęciak R, Sinski E. Asymptomatic babesiosis as a cause of splenomegaly and splenectomy in a dog. Med Wet. 2008;64:441-3.

172. Aktas M, Özübek S, Altay K, Ipek NDS, Balkaya I, Utuk AE, et al. Molecular detection of tick-borne rickettsial and protozoan pathogens in domestic dogs from Turkey. Parasit Vectors. 2015;8:157.

173. Guidi E, Pradier S, Lebert I, Leblond A. Piroplasmosis in an endemic area: analysis of the risk factors and their implications in the control of theileriosis and babesiosis in horses. Parasitol Res. 2015;114:71-83.

174. Waal D, Heerden J. Equine Piroplasmosis. In: Coetzer J, editor. Infect. Dis. Livest. with Spec. Ref. to South. Africa. Cape Town: Oxford University Press; 1994.

175. Bashiruddin JB, Camma C, Rebelo E. Molecular detection of Babesia equi and Babesia caballi in horse blood by PCR amplification of part of the $16 \mathrm{~S}$ rRNA gene. Vet Parasitol. 1999;84:75-83.

176. Sellon D. Disorders of the hematopoietic system. In: Reed S, Bayly W, Sellon D, editors. Equine Intern. Med. 1st ed. Philadelphia: Saunders; 2004. p. 735

177. Allsopp MTEP, Lewis BD, Penzhorn BL. Molecular evidence for transplacental transmission of Theileria equi from carrier mares to their apparently healthy foals. Vet Parasitol. 2007:148:130-6.

178. Egeli AK. Babesiosis in a six-day-old calf. Vet Rec. 1996;139:344-5.

179. Mierzejewska E, Welc-Falęciak R, Bednarska M, Rodo A, Bajer A. The first evidence for vertical transmission of Babesia canis in a litter of Central Asian Shepherd dogs. Ann Agric Environ Med. 2014;21:500-3.

180. Földvári G, Hell E, Farkas R. Babesia canis canis in dogs from Hungary: detection by PCR and sequencing. Vet Parasitol. 2005;127:221-6.

181. Matjila TP, Nijhof AM, Taoufik A, Houwers D, Teske E, Penzhorn BL, et al. Autochthonous canine babesiosis in The Netherlands. Vet Parasitol. 2005;131:23-9.
182. Losson B, Mollet J, Avez F, Malaise F, Mignon B. Description de trois cas autochtones de babesiose canine (Babesia canis) en Belgique. Ann Med Vet. 1999;143:119-24.

183. Øines $\varnothing$, Storli K, Brun-Hansen H. First case of babesiosis caused by Babesia canis canis in a dog from Norway. Vet Parasitol. 2010;171:350-3.

184. Claerebout E, Losson B, Cochez C, Casaert S, Dalemans A-C, De Cat A, et al. Ticks and associated pathogens collected from dogs and cats in Belgium. Parasit Vectors. 2013;6:183

185. Zahler M, Steffen T, Lutz S, Hähnel W-C, Rinder H, Gothe R. Babesia canis und Dermacentor reticulatus in München, ein neuer Naturherd in Deutschland. Tierarztl Prax. 2000:28:116-20.

186. Scoles GA, Ueti MW. Vector ecology of equine piroplasmosis. Annu Rev Entomol. 2015:60:561-80.

187. Friedhoff KT, Tenter AM, Muller I. Haemoparasites of equines: impact on international trade of horses. Rev Sci Tech. 1990:9:1187-94.

188. Mehlhorn H, Schein E. Redescription of Babesia equi Laveran, 1901 as Theileria equi Mehlhorn, Schein 1998. Parasitology Research. 1998;84:467-75.

189. Farkas R, Tánczos B, Gyurkovszky M, Földvári G, Solymosi N. Serological and molecular detection of Theileria equi infection in horses in Hungary. Vet Parasitol. 2013;192:143-8.

190. Enigk K. Further experiments in the transmission of equine piroplasmosis. Arch Wiss Prakt Tierheilk. 1944;79:58-80.

191. Enigk K. The vectors of equine piroplasmosis, their distribution and biology. Arch Wiss Prakt Tierheilk. 1943;78:209-40.

192. Dumler JS, Barbet AF, Bekker CP, Dasch GA, Palmer GH, Ray SC, et al. Reorganization of genera in the families Rickettsiaceae and Anaplasmataceae in the order Rickettsiales: unification of some species of Ehrlichia with Anaplasma, Cowdria with Ehrlichia and Ehrlichia with Neorickettsia, description of six new species combinations and designation of Ehrlichia equi and 'HGE agent' as subjective synonyms of Ehrlichia phagocytophila. Int J Syst Evol Microbiol. 2001;51:2145-65.

193. Atif FA. Anaplasma marginale and Anaplasma phagocytophilum: Rickettsiales pathogens of veterinary and public health significance. Parasitol Res. 2015 114:3941-57.

194. Zivkovic Z, Nijhof AM, de la Fuente J, Kocan KM, Jongejan F. Experimental transmission of Anaplasma marginale by male Dermacentor reticulatus. BMC Vet Res. 2007;3:32

195. Hornok S, Földvári G, Elek V, Naranjo V, Farkas R, de la Fuente J. Molecular identification of Anaplasma marginale and rickettsial endosymbionts in blood-sucking flies (Diptera: Tabanidae, Muscidae) and hard ticks (Acari: Ixodidae). Vet Parasitol. 2008;154:354-9.

196. Hornok S, Micsutka A, de Mera IG F, Meli ML, Gönczi E, Tánczos B, et al. Fatal bovine anaplasmosis in a herd with new genotypes of Anaplasma marginale, Anaplasma ovis and concurrent haemoplasmosis. Res Vet Sci. 2012;92:30-5.

197. Fonville M, Friesema IHM, Hengeveld PD, van Leeuwen AD, Jahfari S, Harms $M G$, et al. Human exposure to tickborne relapsing fever spirochete Borrelia miyamotoi, the Netherlands. Emerg Infect Dis. 2014;20:1244-5.

198. Khasnatinov MA, Liapunov AV, Manzarova EL, Kulakova NV, Petrova IV, Danchinova GA. The diversity and prevalence of hard ticks attacking human hosts in Eastern Siberia (Russian Federation) with first description of invasion of non-endemic tick species. Parasitol Res. 2016;115:501-10.

199. Keirans JE, Durden LA. Invasion: exotic ticks (Acari: Argasidae, Ixodidae) imported into the United States. A review and new records. J Med Entomol United States. 2001:38:850-61.

200. Wójcik-Fatla A, Bartosik K, Buczek A, Dutkiewicz J. Babesia microti in adult Dermacentor reticulatus ticks from eastern Poland. Vector Borne Zoonotic Dis. 2012;12:841-3.

201. Rudolf I, Mendel J, Sikutová S, Svec P, Masařiková J, Nováková D, et al. 16 S rRNA gene-based identification of cultured bacterial flora from host-seeking Ixodes ricinus, Dermacentor reticulatus and Haemaphysalis concinna ticks, vectors of vertebrate pathogens. Folia Microbiol (Praha). 2009;54:419-28.

202. Wojcik-Fatla A, Sroka J, Zajac V, Sawczyn A, Cisak E, Dutkiewicz J. Toxoplasma gondii (Nicolle et Manceaux, 1908) detected in Dermacentor reticulatus (Fabricius) (Ixodidae). Folia Parasitol. (Praha). 2015;62:1-5.

203. Bown KJ, Begon M, Bennett M, Birtles RJ, Burthe S, Lambin X, et al. Sympatric Ixodes trianguliceps and Ixodes ricinus ticks feeding on field voles (Microtus agrestis): potential for increased risk of Anaplasma phagocytophilum in the United Kingdom? Vector-borne Zoonotic Dis. 2006;6:404-10.

204. Bown KJ, Lambin X, Telford GR, Ogden NH, Telfer S, Woldehiwet Z, et al. Relative importance of Ixodes ricinus and Ixodes trianguliceps as vectors for 
Anaplasma phagocytophilum and Babesia microti in field vole (Microtus agrestis) populations. Appl Environ Microbiol. 2008;74:7118-25.

205. Gern L, Rouvinez E, Toutoungi L, Godfroid E. Transmission cycles of Borrelia burgdorferi sensu lato involving Ixodes ricinus and/or I. hexagonus ticks and the European hedgehog, Erinaceus europaeus, in suburban and urban areas in Switzerland. Folia Parasitol (Praha). 1997:44:309-14.

206. Szekeres S, Coipan EC, Rigó K, Majoros G, Jahfari S, Sprong H, et al. Ecoepidemiology of Borrelia miyamotoi and Lyme borreliosis spirochetes in a popular hunting and recreational forest area in Hungary. Parasit Vectors. 2015:8:309.

207. Růžek D, Yakimenko W, Karan LS, Tkachev SE. Omsk haemorrhagic fever. Lancet. 2010;376:2104-13.

208. Belov GF, Tofaniuk E V, Kurzhukov GP, Kuznetsova VG. The clinicoepidemiological characteristics of Omsk hemorrhagic fever in 1988-1992. Zh. Mikrobiol. Epidemiol. Immunobiol. 1995:4:88-91. (In Russian)

209. Kovalev SY, Chernykh DN, Kokorev VS, Snitkovskaya TE, Romanenko W. Origin and distribution of tick-borne encephalitis virus strains of the Siberian subtype in the Middle Urals, the north-west of Russia and the Baltic countries. J Gen Virol. 2009:90:2884-92.

210. Karan LS, Ciccozzi M, Yakimenko W, Lo Presti A, Cella E, Zehender G, et al. The deduced evolution history of Omsk hemorrhagic fever virus. J Med Virol. 2014;86:1181-7.

211. Hoogstraal H. Argasid and nuttalliellid ticks as parasites and vectors. Adv Parasitol. 1985;24:135-238.

212. Lvov OK. Omsk haemorrhagic fever. In: Monath TP, editor. Arboviruses Epidemiol. Ecol. 3rd ed. Boca Raton: CRC Press, Inc; 1988. p. 205-16.

213. Busygin FF. Omsk hemorrhagic fever-current status of the problem. Vopr Virusol. 2000;45:4-9. (In Russian).

214. Chidumayo NN, Yoshii K, Kariwa H. Evaluation of the European tick-borne encephalitis vaccine against Omsk hemorrhagic fever virus. Microbiol Immunol. 2014;58:112-8.

215. Orlinger KK, Hofmeister Y, Fritz R, Holzer GW, Falkner FG, Unger B, et al. A tick-borne encephalitis virus vaccine based on the European prototype strain induces broadly reactive cross-neutralizing antibodies in humans. J Infect Dis. 2011;203:1556-64.

216. Amicizia D, Domnich A, Panatto D, Lai PL, Cristina ML, Avio U, et al. Epidemiology of tick-borne encephalitis (TBE) in Europe and its prevention by available vaccines. Hum Vaccin Immunother. 2013;9:1163-71.

217. Jaenson TGT, Hjertqvist M, Bergström T, Lundkvist A. Why is tick-borne encephalitis increasing? A review of the key factors causing the increasing incidence of human TBE in Sweden. Parasit Vectors. 2012;5:184.

218. Imhoff M, Hagedorn P, Schulze $Y$, Hellenbrand W, Pfeffer M, Niedrig M. Review: Sentinels of tick-borne encephalitis risk. Ticks Tick Borne Dis. 2015;6:592-600

219. Lindquist L. Tick-borne encephalitis. Handb Clin Neurol. 2014;123:531-59.

220. Dobler G, Gniel D, Petermann R, Pfeffer M. Epidemiology and distribution of tick-borne encephalitis. Wien Med Wochenschr. 2012;162:230-8.

221. Bogovic P, Strle F. Tick-borne encephalitis: A review of epidemiology, clinical characteristics, and management. World J Clin cases United States. 2015;3:430-41

222. Šmit R, Postma MJ. Review of tick-borne encephalitis and vaccines: clinical and economical aspects. Expert Rev Vaccines. 2015;14:737-47.

223. Danielová V, Holubová J, Pejcoch M, Daniel M. Potential significance of transovarial transmission in the circulation of tick-borne encephalitis virus. Folia Parasitol (Praha). 2002:49:323-5.

224. Socolovschi C, Bitam I, Raoult D, Parola P. Transmission of Rickettsia conorii conorii in naturally infected Rhipicephalus sanguineus. Clin Microbiol Infect. 2009;15 Suppl 2:319-21.

225. Nuttall PA, Jones LD, Labuda M, Kaufman WR. Adaptations of arboviruses to ticks. J Med Entomol. 1994:31:1-9.

226. Havlikova S, Lickova M, Klempa B. Non-viraemic transmission of tick-borne viruses. Acta Virol. 2013:57:123-9.

227. Randolph SE, Rogers DJ. Fragile transmission cycles of tick-borne encephalitis virus may be disrupted by predicted climate change. Proc $\mathrm{R}$ Soc London B Biol Sci. 2000;267:1741-4.

228. Wójcik-Fatla A, Cisak E, Zając V, Zwoliński J, Dutkiewicz J. Prevalence of tick-borne encephalitis virus in Ixodes ricinus and Dermacentor reticulatus ticks collected from the Lublin region (eastern Poland). Ticks Tick Borne Dis. 2011;2:16-9.

229. Stefanoff $P$, Pfeffer M, Hellenbrand W, Rogalska J, Ruhe F, Makowka A, et al. Virus detection in questing ticks is not a sensitive indicator for risk assessment of tick-borne encephalitis in humans. Zoonoses Public Health. 2013:60:215-26.

230. Zöldi V, Juhász A, Nagy C, Papp Z, Egyed L. Tick-borne encephalitis and Lyme disease in Hungary: the epidemiological situation between 1998 and 2008. Vector Borne Zoonotic Dis. 2013;13:256-65.

231. Balogh Z, Ferenczi E, Szeles K, Stefanoff P, Gut W, Szomor KN, et al. Tickborne encephalitis outbreak in Hungary due to consumption of raw goat milk. J Virol Methods. 2010;163:481-5.

232. Karbowiak G, Biernat B, Werszko J, Rychlik L. The transstadial persistence of tick-borne encephalitis virus in Dermacentor reticulatus ticks in natural conditions. Acta Parasitol. 2016;61:201-3.

233. Lakos A. Tick-borne lymphadenopathy-a new rickettsial disease? Lancet. 1997:350:1006.

234. Raoult D, Berbis P, Roux V, Xu W, Maurin M. A new tick-transmitted disease due to Rickettsia slovaca. Lancet. 1997:350:112-3.

235. Oteo JA, Portillo A. Tick-borne rickettsioses in Europe. Ticks Tick Borne Dis. 2012;3:271-8.

236. Silva-Pinto A, Santos Mde L, Sarmento A. Tick-borne lymphadenopathy, an emerging disease. Ticks Tick Borne Dis. 2014;5:656-9.

237. Lakos A. Tick-borne lymphadenopathy (TIBOLA). Wien Klin Wochenschr. 2002;114:648-54.

238. Parola P, Rovery C, Rolain JM, Brouqui P, Davoust B, Raoult D. Rickettsia slovaca and $R$. raoultii in tick-borne rickettsioses. Emerg Infect Dis. 2009;15:1105-8.

239. Portillo A, Santibanez S, Garcia-Alvarez L, Palomar AM, Oteo JA. Rickettsioses in Europe. Microbes Infect. 2015;17:834-8.

240. Sprong H, Wielinga PR, Fonville M, Reusken C, Brandenburg AH, Borgsteede $\mathrm{F}$, et al. Ixodes ricinus ticks are reservoir hosts for Rickettsia helvetica and potentially carry flea-borne Rickettsia species. Parasit Vectors. 2009;2:41.

241. Martello E, Selmi M, Ragagli C, Ambrogi C, Stella MC, Mannelli A, et al. Rickettsia slovaca in immature Dermacentor marginatus and tissues from Apodemus spp. in the northern Apennines, Italy. Ticks Tick Borne Dis. 2013:4:518-21.

242. Matsumoto K, Ogawa M, Brouqui P, Raoult D, Parola P, Zemtsova G, et al. Transmission of Rickettsia massiliae in the tick, Rhipicephalus turanicus. Med Vet Entomol. 2005;19:263-70.

243. Duscher GG, Hodžić A, Weiler M, Vaux AGC, Rudolf I, Sixl W, et al. First report of Rickettsia raoultii in field collected Dermacentor reticulatus ticks from Austria. Ticks Tick. Borne. Dis. 2016;in press.

244. Ionita M, Silaghi C, Mitrea IL, Edouard S, Parola P, Pfister K. Molecular detection of Rickettsia conorii and other zoonotic spotted fever group rickettsiae in ticks, Romania. Ticks Tick Borne Dis. 2016;7:150-3.

245. Špitalská E, Štefanidesová K, Kocianová E, Boldiš V. Rickettsia slovaca and Rickettsia raoultii in Dermacentor marginatus and Dermacentor reticulatus ticks from Slovak Republic. Exp Appl Acarol. 2012;57:189-97.

246. Tijsse-Klasen E, Jameson LJ, Fonville M, Leach S, Sprong H, Medlock JM. First detection of spotted fever group rickettsiae in Ixodes ricinus and Dermacentor reticulatus ticks in the UK. Epidemiol Infect. 2011;139:524-9.

247. Radzijevskaja J, Paulauskas A, Aleksandraviciene A, Jonauskaite I, Stanko M, Karbowiak G, et al. New records of spotted fever group rickettsiae in Baltic region. Microbes Infect. 2015;17:874-8.

248. Wojcik-Fatla A, Cisak E, Zajac V, Sroka J, Sawczyn A, Dutkiewicz J. Study on tick-borne rickettsiae in eastern Poland. I. Prevalence in Dermacentor reticulatus (Acari: Amblyommidae). Ann Agric Environ Med. 2013;20:276-9.

249. Szekeres S, Docters Van Leeuwen A, Rigó K, Jablonszky M, Majoros G, Sprong $\mathrm{H}$, et al. Prevalence and diversity of human pathogenic rickettsiae in urban versus rural habitats, Hungary. Exp Appl Acarol. 2016;68:223-6.

250. Dobec M, Golubic D, Punda-Polic V, Kaeppeli F, Sievers M. Rickettsia helvetica in Dermacentor reticulatus ticks. Emerg Infect Dis. 2009;15:98-100.

251. Petersen JM, Mead PS, Schriefer ME. Review article Francisella tularensis: an arthropod-borne pathogen. Vet Res. 2009:40:7.

252. Petrov VG, Olsuf'yev NG. [Proliferation of Bacterium tularense in cells of Dermacentor pictus Herm. in the course of metamorphosis]. Vopr. krayevoy, Obs. Eksp. Parazitol. i meditsinskoy Zool. (Problems Reg. Gen. Exp. Parasitol. Med. Zool. Moscow. 1953;8:149-156. (In Russian).

253. Markowitz LE, Hynes NA, de la Cruz P, Campos E, Barbaree JM, Plikaytis BD, et al. Tick-borne tularemia. An outbreak of lymphadenopathy in children. JAMA. 1985;254:2922-5.

254. Boone I, Hassler D, Nguyen T, Splettstoesser WD, Wagner-Wiening C, Pfaff G. Tularaemia in southwest Germany: Three cases of tick-borne transmission. Ticks Tick Borne Dis. 2015;6:611-4. 
255. Genchi M, Prati P, Vicari N, Manfredini A, Sacchi L, Clementi E, et al. Francisella tularensis: No evidence for transovarial transmission in the tularemia tick vectors Dermacentor reticulatus and Ixodes ricinus. PLoS One. 2015;10:e0133593.

256. Rehacek J, Kovacova E, Ciampor F, Gresikova M, Tarasevich IV. Experimenta double infection with Coxiella burnetii and tick-borne encephalitis virus in Dermacentor reticulatus ticks. Acta Virol. 1987;31:65-73.

257. Sting R, Breitling N, Oehme R, Kimmig P. The occurrence of Coxiella burnetii in sheep and ticks of the genus Dermacentor in Baden-Wuerttemberg. Dtsch Tierarztl Wochenschr. 2004;111:390-4. In German.

258. Duron O, Sidi-Boumedine K, Rousset E, Moutailler S, Jourdain E. The importance of ticks in $\mathrm{Q}$ fever transmission: What has (and has not) been demonstrated? Trends Parasitol. 2015:31:536-52.

259. Filchagov AV, Lebedeva NN. Study of ecology of hungry larvae of Dermacentor reticulatus and their links with hosts under natural conditions. Parazitologiia. 1988;22:366-71 (In Russian).

260. Burkhardt JF, Schlund W. Rötelmaus Clethrionomys glareolus (Schreber, 1780). In: Braun M, Dieterlen F, editors. Die Säugetiere Baden-Württembergs, vol. 2. Stuttgart: Ulmer Verlag; 2005

261. Schröpfer R. Gelbhalsmaus-Apodemus flavicollis (Melchior, 1834). Schröpfer, R., Feldmann, R., Vierhaus, H. (Eds.), Die Säugetiere Westfalens. Münster: Abhandlungen des Westfälischen Museums für Naturkunde, vol. 46. 1984. p. 196-204.

262. Löhrl H. Ökologische und physiologische Studien an einheimischen Muriden und Soriciden. Z Saugetierkd. 1938;13:114-60.

263. Zejda J. Small mammals in certain forest type groups in southern Moravia. Zool List. 1973;22:1-12.

264. Dizij A, Kurtenbach K. Clethrionomys glareolus, but not Apodemus flavicollis, acquires resistance to Ixodes ricinus L., the main European vector of Borrelia burgdorferi. Parasite Immunol. 1995;17:177-83.

265. Randolph SE. Population regulation in ticks: the role of acquired resistance in natural and unnatural hosts. Parasitology. 1979;79:141-56.

266. Randolph SE. Density-dependent acquired resistance to ticks in natural hosts, independent of concurrent infection with Babesia microti. Parasitology. 1994;108:413-9.

267. Samoylenko I, Shpynov S, Raoult D, Rudakov N, Fournier P-E. Evaluation of Dermacentor species naturally infected with Rickettsia raoultii. Clin Microbiol Infect. 2009;15 Suppl 2:305-6.

268. European Centre for Disease Prevention and Control [Internet]. [cited 2015 Nov 11]. Available from: http://ecdc.europa.eu/en/healthtopics/vectors/ vector-maps/Pages/VBORNET-maps-tick-species.aspx

269. Dyl'ko N. [Data on babesiosis of large cattle distributed in the lower reaches of Goryn' River. Avtoref. Diss. Kand. Leningrad. Thesis]. 1953.

270. Buczek A, Lachowska-Kotowska P, Bartosik K. The effect of synthetic pyrethroids on the attachment and host-feeding behaviour in Dermacentor reticulatus females (Ixodida: Amblyommidae). Parasit Vectors. 2015:8:366

271. Taenzler J, Liebenberg J, Roepke RKA, Heckeroth AR. Prevention of transmission of Babesia canis by Dermacentor reticulatus ticks to dogs treated orally with fluralaner chewable tablets $\left(\right.$ Bravecto $\left.^{\mathrm{TM}}\right)$. Parasit Vectors. 2015;8:305.

272. Dumont P, Fourie JJ, Soll M, Beugnet F. Repellency, prevention of attachment and acaricidal efficacy of a new combination of fipronil and permethrin against the main vector of canine babesiosis in Europe, Dermacentor reticulatus ticks. Parasit Vectors. 2015;8:50.

273. Navarro C, Reymond N, Fourie J, Hellmann K, Bonneau S. Prevention of Babesia canis in dogs: efficacy of a fixed combination of permethrin and fipronil $\left(\right.$ Effitix $^{\circledast}$ ) using an experimental transmission blocking model with infected Dermacentor reticulatus ticks. Parasit Vectors. 2015;8:32.

274. Beugnet F, Halos L, Larsen D, Labuschagné M, Erasmus H, Fourie J. The ability of an oral formulation of afoxolaner to block the transmission of Babesia canis by Dermacentor reticulatus ticks to dogs. Parasit Vectors. 2014;7:283

275. Jongejan F, de Vos C, Fourie JJ, Beugnet F. A novel combination of fipronil and permethrin (Frontline Tri-Act ${ }^{\oplus} /$ Frontect $^{\oplus}$ ) reduces risk of transmission of Babesia canis by Dermacentor reticulatus and of Ehrlichia canis by Rhipicephalus sanguineus ticks to dogs. Parasit Vectors. 2015;8:602.

276. Becskei C, Geurden T, Erasmus H, Cuppens O, Mahabir SP, Six RH. Comparative speed of kill after treatment with Simparica(TM)(sarolaner) and Advantix((R))(imidacloprid + permethrin) against induced infestations of Dermacentor reticulatus on dogs. Parasit Vectors. 2016;9:104
277. Rehbein S, Fourie JJ, de Vos C, Anderson A, Larsen DL, Jeannin P. Efficacy of oral afoxolaner plus milbemycin oxime chewables against induced infestations with Dermacentor reticulatus in dogs. Parasitol Res. 2016;115:1845-51.

278. Facts and Figures About the UK Animal Medicines Industry [Internet]. 2015 [cited 2015 Nov 10]. Available from: http://www.noah.co.uk/focus/facts figures.htm

279. Lebedev A. The bionomics of the tick Dermacentor pictus Herm. on basis of observations carried out in the forest-steppe of western Siberia. Zool. Zh. 1957:36:1016-25.

280. Gilot B, Robin Y, Pautou G, Moncada E, Vigny F. Ecologie et role pathogéne de Dermacentor reticulatus (Fabricius 1795) (Ixodoidea) dans le sud est de la France. Acarologia. 1974;16:220-49.

281. Szymanski S. Seasonal activity of Dermacentor reticulatus (Fabricius, 1794)(Ixodidea) in Poland. III. Larvae and nymphs. Acta Parasitol Pol. 1987:32:265-80

282. Sagdieva PD, Tsikhistavi SG, Nikulina NA. The ectoparasites of small rodents in the Great Caucasus. Soobshcheniya Akad Nauk Gruz SSR. 1988;1291:165-8. (In Russian)

283. Snow KR. Larvae of the British Metastriata (Ixodoidea: Ixodidae). Parasitology. 1972;65:447-55.

284. Lamontellerie M. Les tiques (Acarina, Ixodoidea) du sud-ouest de la France. Ann Parasitol. 1965;40:87-100.

285. Panas $\mathrm{E}$, Leger $\mathrm{N}$, Kretz JL, Dumesnil C. Les Ixodidea de la région Champagne-Ardennes. Etude préliminaire. Acarologia. 1976;18:51-5.

286. Sobrino R, Millán J, Oleaga A, Gortázar C, de la Fuente J, Ruiz-Fons F. Ecological preferences of exophilic and endophilic ticks (Acari: Ixodidae) parasitizing wild carnivores in the Iberian Peninsula. Vet Parasitol. 2012;184:248-57.

287. Gilot B. Les tiques du chien dans le sud-est de la France. Notes sur la biologie de Dermacentor reticulatus (Fabricius, 1794)(Ixodoidea, Ixodidae). Anim Cie. 1974:9:109-24.

288. Biadun W, Rzymowska J, Stepien-Rukasz H, Niemczyk M, Chybowski J. Occurrence of Borrelia burgdorferi sensu lato in Ixodes ricinus and Dermacentor reticulatus ticks collected from roe deer and deer shot in the south-east of Poland. Bull Vet Inst Pulawy. 2007;51:213-7.

289. Bogdaszewska Z. Range and ecology of Dermacentor reticulatus (Fabricius, 1794) in Mazuria focus. IV. Host specificity. Wiad Parazytol. 2005:51:39-42. In Polish.

290. Matsumoto K, Grzeszczuk A, Brouqui P, Raoult D. Rickettsia raoultii and Anaplasma phagocytophilum in Dermacentor reticulatus ticks collected from Bialowieza Primeval Forest European bison (Bison bonasus bonasus), Poland. Clin Microbiol Infect. 2009;15:286-7.

291. Izdebska JN. Observations on the presence of ticks (Acari: Ixodidae) in European bison (Bison bonasus) in Poland. In: Buczek A, Błaszak C, editors. Parasite-Host Relationships. Lublin: Liber; 2004. p. 45-51.

292. Karbowiak G, Izdebska JN, Czaplińska U, Wita I. Cases of survival of the winter by Ixodidae ticks on the hosts in the Białowieża primeval forest. In: Buczek A, Błaszak C, editors. Arthropods and hosts. Lublin: Liber; 2003. p. 77-82.

293. García-Pérez AL, Oporto B, Espí A, del Cerro A, Barral M, Povedano I, et al. Anaplasmataceae in wild ungulates and carnivores in northern Spain. Ticks Tick. Borne. Dis. 2016;7:264-9.

294. Doby JM, Bigaignon G, Aubert M, Imbert G. Ectoparasites de renard et borréliose de Lyme. Recherche de Borrelia burgdorferi chez les tiques Ixodidea et insectes Siphonaptera. Bull Soc Fr Parasitol. 1991;9:279-88.

295. Sréter T, Széll Z, Varga I. Ectoparasite infestations of red foxes (Vulpes vulpes) in Hungary. Vet Parasitol. 2003;115:349-54.

296. Dominguez-Penafiel G, Gimenez-Pardo C, Gegundez M, Lledo L. Prevalence of ectoparasitic arthropods on wild animals and cattle in the Las Merindades area (Burgos, Spain). Parasite. 2011;18:251-60.

297. Hornok S, Horváth G, Jongejan F, Farkas R. Ixodid ticks on ruminants, with on-host initiated moulting (apolysis) of Ixodes, Haemaphysalis and Dermacentor larvae. Vet Parasitol. 2012;187:350-3.

298. Hornok S, Tánczos B, de Mera IG F, de la Fuente J, Hofmann-Lehmann R, Farkas R. High prevalence of Hepatozoon-infection among shepherd dogs in a region considered to be free of Rhipicephalus sanguineus. Vet Parasitol. 2013;196:189-93.

299. Kozuch O, Nosek J. Transmission of tick-borne encephalitis (TBE) virus by Dermacentor marginatus and D. reticulatus ticks. Acta Virol. 1971;15:334.

300. Svehlová A, Berthová L, Sallay B, Boldiš V, Sparagano OAE, Spitalská E. Sympatric occurrence of Ixodes ricinus, Dermacentor reticulatus and Haemaphysalis concinna ticks and Rickettsia and Babesia species in Slovakia. Ticks Tick Borne Dis. 2014;5:600-5. 
301. Mediannikov O, Matsumoto K, Samoylenko I, Drancourt M, Roux V, Rydkina E, et al. Rickettsia raoultii sp. nov., a spotted fever group rickettsia associated with Dermacentor ticks in Europe and Russia. Int J Syst Evol Microbiol. 2008; 58:1635-9.

302. Potkonjak A, Gutiérrez R, Savić S, Vračar V, Nachum-Biala Y, Jurišić A, et al. Molecular detection of emerging tick-borne pathogens in Vojvodina, Serbia. Ticks Tick Borne Dis. 2016;7:199-203.

303. Hornok S, Meli ML, Perreten A, Farkas R, Willi B, Beugnet F, et al. Molecular investigation of hard ticks (Acari: Ixodidae) and fleas (Siphonaptera: Pulicidae) as potential vectors of rickettsial and mycoplasmal agents. Vet Microbiol. 2010;140:98-104.

304. Rehacek J, Nosek J, Urvolgyi J, Sztankay M. Rickettsiae of the spotted fever group in Hungary. Folia Parasitol (Praha). 1979;26:367-71.

305. Wójcik-Fatla A, Zając V, Sawczyn A, Cisak E, Dutkiewicz J. Babesia spp. in questing ticks from eastern Poland: prevalence and species diversity. Parasitol. Res. 2015;114:3111-6.

306. de la Fuente J, Estrada-Pena A, Venzal JM, Kocan KM, Sonenshine DE. Overview: Ticks as vectors of pathogens that cause disease in humans and animals. Front. Biosci. 2008;13:6938-6946.

307. García-Sanmartín J, Barandika JF, Juste RA, García-Pérez AL, Hurtado A. Distribution and molecular detection of Theileria and Babesia in questing ticks from northern Spain. Med Vet Entomol. 2008;22:318-25.

308. Bouwknegt C, van Rijn PA, Schipper JJM, Hölzel D, Boonstra J, Nijhof AM, et al. Potential role of ticks as vectors of bluetongue virus. Exp Appl Acarol. 2010;52:183-92

309. Labuda M, Alves MJ, Eleckova E, Kozuch O, Filipe AR. Transimission of tickborne bunyaviruses by cofeeding ixodid ticks. Acta Virol. 1997;41:325-8.

310. Kúdelová M, Belvončíková P, Vrbová M, Koval'ová A, Štibrániová I, Kocáková P, et al. Detection of Murine Herpesvirus 68 (MHV-68) in Dermacentor reticulatus ticks. Microb Ecol. 2015;70:785-94.

311. Shpynov SN, Fournier P-E, Rudakov NV, Samoilenko IE, Reshetnikova TA, Yastrebov VK, et al. Molecular identification of a collection of spotted fever group Rickettsiae obtained from patients and ticks from Russia. Am J Trop Med Hyg. 2006;74:440-3.

312. Korshunova OS, Zhmaeva ZM, Miasnikov IA, Katelina AF. On a natural focus of tick exanthematous typhus in Tula District. Med Parazitol (Mosk) USSR. 1966;35:470-4. (In Russian).

313. Szekeres S, Coipan EC, Rigó K, Majoros G, Jahfari S, Sprong H, et al. Candidatus Neoehrlichia mikurensis and Anaplasma phagocytophilum in natural rodent and tick communities in Southern Hungary. Ticks Tick Borne Dis. 2015;6:111-6.

314. Wirtgen M, Nahayo A, Linden A, Losson B, Garigliany M, Desmecht D. Detection of Anaplasma phagocytophilum in Dermacentor reticulatus ticks. Vet Rec. 2011;168:195.

315. Kahl O, Janetzki C, Gray JS, Stein J, Bauch RJ. Tick infection rates with Borrelia: Ixodes ricinus versus Haemaphysalis concinna and Dermacentor reticulatus in two locations in eastern Germany. Med Vet Entomol. 1992;6:363-6.

316. Król N, Kiewra D, Szymanowski M, Lonc E. The role of domestic dogs and cats in the zoonotic cycles of ticks and pathogens. Preliminary studies in the Wrocław Agglomeration (SW Poland). Vet Parasitol. 2015;214:208-12.

317. Rehacek J, Urvolgyi J, Kocianova E, Sekeyova Z, Vavrekova M, Kovacova E. Extensive examination of different tick species for infestation with Coxiella burnetii in Slovakia. Eur J Epidemiol. 1991;7:299-303.

318. Hubalek Z, Sixl W, Halouzka J, Mikulaskova M. Prevalence of Francisella tularensis in Dermacentor reticulatus ticks collected in adjacent areas of the Czech and Austrian Republics. Cent Eur J Public Health. 1997:5:199-201.

319. Vyrostekova V, Khanakah G, Kocianova E, Gurycova D, Stanek G. Prevalence of coinfection with Francisella tularensis in reservoir animals of Borrelia burgdorferi sensu lato. Wien Klin Wochenschr. 2002;114:482-8.

320. Wójcik-Fatla A, Zając V, Sawczyn A, Cisak E, Sroka J, Dutkiewicz J. Occurrence of Francisella spp. in Dermacentor reticulatus and Ixodes ricinus ticks collected in eastern Poland. Ticks Tick Borne Dis. 2015;6:253-7.

321. Sréter-Lancz Z, Széll Z, Sréter T, Márialigeti K. Detection of a novel Francisella in Dermacentor reticulatus: a need for careful evaluation of PCR-based identification of Francisella tularensis in Eurasian ticks. Vector-Borne Zoonotic Dis. 2009;9:123-6.

322. Kreizinger Z, Hornok S, Dan A, Hresko S, Makrai L, Magyar T, et al. Prevalence of Francisella tularensis and Francisella-like endosymbionts in the tick population of Hungary and the genetic variability of Francisella-like agents. Vector Borne Zoonotic Dis. 2013;13:160-3.
323. Gehringer H, Schacht E, Maylaender N, Zeman E, Kaysser P, Oehme R, et al. Presence of an emerging subclone of Francisella tularensis holarctica in Ixodes ricinus ticks from south-western Germany. Ticks Tick Borne Dis. 2013;4:93-100.

324. de Carvalho IL, Santos N, Soares T, Ze-Ze L, Nuncio MS. Francisella-like endosymbiont in Dermacentor reticulatus collected in Portugal. Vector Borne Zoonotic Dis. 2011;11:185-8.

325. Egyed L, Makrai L. Cultivable internal bacterial flora of ticks isolated in Hungary. Exp Appl Acarol. 2014;63:107-22.

326. Renvoise A, Harle JR, Raoult D, Roux V. Gordonia sputi bacteremia. Emerg Infect Dis. 2009;15:1535-7.

327. Kim A. Ixodid ticks as possible reservoirs and transmitters of Salmonella. Vopr Prir Ochagovosti Bolezn. 1979;10:98-108. (In Russian).

328. Kondrashova ZN, Kotel'nikova GM. The interrelationship between $S$. typhimurium and ixodes ticks. Zh Mikrobiol Epidemiol Immunobiol USSR. 1973:50:135. (In Russian).

329. Gray J, Zintl A, Hildebrandt A, Hunfeld K, Weiss L. Zoonotic babesiosis : Overview of the disease and novel aspects of pathogen identity. Ticks Tick Borne Dis. 2010;1:3-10.

330. Rehacek J, Kovacova E, Kocianova E. Isolation of Nosema slovaca (Microsporidiae) from Dermacentor reticulatus ticks (Acari: Ixodidae) collected in Hungary. Exp Appl Acarol. 1996;20:57-60.

\section{Submit your next manuscript to BioMed Central and we will help you at every step:}

- We accept pre-submission inquiries

- Our selector tool helps you to find the most relevant journal

- We provide round the clock customer support

- Convenient online submission

- Thorough peer review

- Inclusion in PubMed and all major indexing services

- Maximum visibility for your research

Submit your manuscript at www.biomedcentral.com/submit

) Biomed Central 